\title{
Zebrafish larvae as a powerful model to dissect protective innate immunity in response to Legionella pneumophila infection
}

\author{
Flávia Viana ${ }^{1, \S, \#, *}$, Laurent Boucontet ${ }^{2, \S}$, Daniel Schator ${ }^{1,3}$, Valerio Laghi $^{2}$, Marine Ibranosyan ${ }^{4}$, Sophie \\ Jarraud $^{4,5}$, Emma Colucci-Guyon ${ }^{2, \epsilon, *}$ and Carmen Buchrieser ${ }^{1, €, *}$ \\ ${ }^{1}$ Institut Pasteur, Biologie des Bactéries Intracellulaires and CNRS UMR 3525, 75724, Paris, France, \\ ${ }^{2}$ Institut Pasteur, Unité Macrophages et Développement de I'Immunité and CNRS UMR 3738, Paris, \\ France, ${ }^{3}$ Sorbonne Université, Collège doctoral, 75005 Paris, France, ${ }^{4}$ National Reference Centre of \\ Legionella, Institute of Infectious Agents, Hospices Civils de Lyon, Lyon, France, ${ }^{4}$ Hospices Civils de \\ Lyon, Centre National de Référence des Legionella, Lyon, France, ${ }^{5}$ Centre International de Recherche \\ en Infectiologie, Université Lyon 1, UMR CNRS 5308, Inserm U1111, ENS de Lyon, Lyon, France
}

\#Present Address: Wellcome-Wolfson Institute for Experimental Medicine, Queen's University Belfast, Belfast, United Kingdom

$\S$ These authors contributed equally

$€$ Co-last authors

*Corresponding author's: cbuch@pasteur.fr, emma.colucci@pasteur.fr, f.d.m.viana@gmail.com

Key words: Legionella pneumophila, zebrafish, innate immune response; live imaging; neutrophils; macrophages

Lead contact:

Carmen Buchrieser

Institut Pasteur

Biologie des Bactéries Intracellulaires

28, rue du Dr. Roux,

75724 Paris Cedex 15, France

Tel: (33-1)-45-68-83-72

E-mail: cbuch@pasteur.fr 
bioRxiv preprint doi: https://doi org/10.1101/2021 10.18.464513. this version posted October 19, 2021. The copyright holder for this preprint (which was not certified by peer review) is the author/funder, who has granted bioRxiv a license to display the preprint in perpetuity. It is made available under aCC-BY-NC-ND 4.0 International license.

\section{Abstract}

39 The zebrafish has become a powerful model organism to study host-pathogen interactions. Here, we

40 developed a zebrafish model of Legionella pneumophila infection to dissect innate immune

41 responses. We show that L. pneumophila cause zebrafish larvae death in a dose dependent manner,

42 and that macrophages are the first line of defence, with neutrophils cooperating to clear the

43 infection. When either macrophages or neutrophils are depleted, the larvae become lethally

44 sensitive to L. pneumophila. As observed in human infections, the adaptor signalling molecule Myd88

45 is not required to control disease in the larvae. Furthermore, proinflammatory cytokines IL-1 $\beta$ and

46 TNF $\alpha$ were upregulated during infection, recapitulating key immune responses seen in human

47 infection. We also uncovered a previously undescribed phenotype in zebrafish larvae, whereby

48 bloodborne, wild type L. pneumophila invade and grow in the larval yolk region but not a T4SS

49 mutant. Zebrafish larva represent an innovative L. pneumophila infection model closely mimicking

50 important aspects of human infection.

51

52

53 
bioRxiv preprint doi: https://doi.org/10.1101/2021.10.18.464513; this version posted October 19, 2021. The copyright holder for this preprint (which was not certified by peer review) is the author/funder, who has granted bioRxiv a license to display the preprint in perpetuity. It is made available under aCC-BY-NC-ND 4.0 International license.

\section{INTRODUCTION}

Legionella pneumophila, a gram negative, facultative intracellular bacterium inhabits natural, freshwater sources ${ }^{1,2}$. As an environmental, aquatic microbe L. pneumophila replicates intracellularly in aquatic protozoa ${ }^{3}$. Most interestingly, in contrast to other intracellular pathogens L. pneumophila is not adapted to a single host, but it exhibits a broad host range including Amoebozoa (amoebae), Percolozoa (excavates) and Ciliophora (ciliated protozoa) ${ }^{3,4}$. In the environment L. pneumophila can also be found within biofilms where it acquires nutrients from this mixed community, but it can also survive in a planktonic form for a certain time as well ${ }^{5}$. As fresh water and man-made systems are connected, L. pneumophila can also contaminate artificial water systems. Protected in its protozoan hosts $L$. pneumophila survives water disinfectants and may gain access to humans via aerosols produced by different man-made structures and devices. The inhalation of L. pneumophila contaminated aerosols can cause a severe pneumonia, the so-called Legionnaires' disease ${ }^{6}$. However, not every infection leads to disease. Disease outcome is determined by virulence of the bacterial strain, bacterial burden in the inhaled aerosols and most importantly by the host immune status. Host factors determining susceptibility include age above 50 , smoking and/or having chronic lung disease, being immunocompromised and genetic factors that alter the immune response ${ }^{2,7,8}$. Once the bacteria reach the lungs of susceptible individuals, they can infect alveolar macrophages and replicate therein. After being phagocytosed L. pneumophila avoids lysosomes and establishes an endoplasmic reticulum derived vacuole named the Legionella containing vacuole (LCV) ${ }^{9,10}$. The LCV, a safe haven for bacterial replication, is established by utilizing the Dot/Icm type IV secretion system (T4SS) that injects over 350 proteins into the host cell ${ }^{9-11}$. These effector proteins manipulate a myriad of host pathways to recruit vesicles derived from the endoplasmic reticulum to the LCV, to supply the bacteria with nutrients, restrain autophagy and supress apoptosis or to subvert the host cell immune response ${ }^{9-11}$. A surprising high number of these effectors mimic host proteins and encode eukaryotic functions helping L. pneumophila to subvert numerous host pathways in remarkable diverse ways ${ }^{11-13}$

Intracellular bacterial replication and innate immune responses have been studied in vitro using both murine and human cell lines and in vivo using different animal models of L. pneumophila infection. However, results obtained with these models cannot be easily extrapolated to what is observed in human disease. Studies in invertebrate models, for example in Galleria mellonella and Caenorhabditis elegans, ${ }^{14,15}$ require further validation in more developed models as their immune system greatly differs from that of vertebrates. More interestingly, mouse infection fails to recall the human disease phenotype, as most inbred mice strains are naturally resistant to L. pneumophila ${ }^{16}$. Very early after the discovery of L. pneumophila the guinea pig model of Legionnaires' disease was developed. Guinea pigs are highly susceptible to L. pneumophila when infected through injection into 
bioRxiv preprint doi: https://doi.org/10.1101/2021.10.18.464513; this version posted October 19, 2021. The copyright holder for this preprint (which was not certified by peer review) is the author/funder, who has granted bioRxiv a license to display the preprint in perpetuity. It is made available under aCC-BY-NC-ND 4.0 International license.

the peritoneum ${ }^{6}$ or when exposed to L. pneumophila containing aerosols ${ }^{6}$. Several studies thereafter have shown that the guinea pig infection model recalls human disease and allows to study the immune response to $L$. pneumophila infection ${ }^{17,18}$. However, the guinea pig model is now rarely used due to the limited availability of specific immunological reagents for these animals and the demanding laboratory and husbandry requirements to work with guinea pigs.

Since the above-mentioned models, including the widely used murine models, are limited for studying L. pneumophila infection in vivo and discrepancies exist between results obtained in mouse or human cells, the development of new, alternative models for Legionella infection is important. The zebrafish (Danio rerio) originally introduced as a model organism in developmental biology has emerged in recent years as a powerful non-mammalian model to study nearly every aspect of biology, including immune cell behaviour and host-pathogen interactions ${ }^{19,20}$. Zebrafish are evolutionary closer to humans than fruit flies and nematodes, easier to manipulate than mice and their immune system is remarkably similar to the one of mammals, making them an attractive laboratory model for immunology and infection biology ${ }^{19,20}$. Its popularity is also due to its small size and the natural translucency of its embryos and larvae, which makes it possible to follow leukocyte behaviour and infection onset at the level of the whole organism in real-time and high resolution ${ }^{21}$. Additionally, although adult organisms display a fully developed immune system with both active innate and adaptive branches, studies can also be conducted at the early stages of life (embryonic or larvae) when the organism solely relies on innate immunity, allowing to dissect the mechanisms arising from different immune responses ${ }^{21-23}$. Thus, we sought to examine whether the zebrafish could be an alternative model for analysing host-pathogen interactions and the innate immune response to L. pneumophila infection.

We show that L. pneumophila infection of zebrafish larvae recapitulate human disease onset, as infected wild-type larvae are generally able to clear the infection, but immunocompromised fish fail to do so. Both macrophages and neutrophils quickly interact and engulf injected $L$. pneumophila. Macrophage-depleted larvae show a dramatic increase of bacterial burden concomitant with host death, pointing to a crucial role of macrophages in controlling the infection. Interestingly, we discovered a new infection phenotype, as L. pneumophila replicates in the larvae yolk region, where it seems to be able to avoid the immune response of the host.

\section{RESULTS}

\section{L. pneumophila infection induces mortality in zebrafish larvae in a dose dependent manner}

To analyse whether L. pneumophila can cause disease in zebrafish larvae we microinjected larvae 72 hours post fertilisation (hpf) intravenously in the caudal vessels near the cloaca (UGO) (Fig 1A), with $10^{3}$ or $10^{4}$ CFU of wild type (WT) L. pneumophila strain Paris expressing GFP (WT-GFP) or the type IV 
bioRxiv preprint doi: https://doi.org/10.1101/2021.10.18.464513; this version posted October 19, 2021. The copyright holder for this preprint (which was not certified by peer review) is the author/funder, who has granted bioRxiv a license to display the preprint in perpetuity. It is made available under aCC-BY-NC-ND 4.0 International license. death of zebrafish larvae. Larvae that were unable to control infection by $72 \mathrm{hpi}$, showed a unique

secretion system (T4SS) deficient isogenic mutant expressing GFP ( $\triangle \operatorname{dot} A-\mathrm{GFP})$. The infected larvae were kept at $28^{\circ} \mathrm{C}$ and were monitored regularly until 72 hours post infection (hpi) to record survival or death using a stereomicroscope. Larvae infected with doses of up to $3 \times 10^{3}$ CFU of WT-GFP (defined as low dose, LD) all survived (100\% survival). In contrast, larvae infected intravenously with doses of $10^{4} \mathrm{CFU}$ (defined as high dose, HD) resulted in approximately $30 \%$ of death within $72 \mathrm{hpi}$ (Fig 1B). Importantly, all larvae injected with LD or HD of the $\triangle \operatorname{dotA-GFP}$ strain survived for the entire time of observation (Fig 1B) indicating that the T4SS is important for replication in zebrafish larvae as it is in other infection models and in humans.

We then set up a method to monitor the bacterial burden of the infected zebrafish larvae. The progression of the infection was followed by analysing the bacterial load at 0, 24, 48 and $72 \mathrm{hpi}$ comparing three different methods. First, we quantified the pixel counts of GFP fluorescence of live larvae images (Fig. S1A), secondly, we analysed the number of GFP expressing bacteria present in lysed infected larvae by FACS (Fig. S1B) and thirdly we plated serial dilutions of homogenates of euthanized larvae on BCYE medium (Fig S1C). The results obtained with the three methods were comparable (Fig S1). We choose to routinely monitor the L. pneumophila load of zebrafish larvae by FACS. As shown in Fig. 1C, larvae injected with LD of WT-GFP progressively eliminate the bacteria, by $24 \mathrm{hpi}$. Similarly, with high doses of $\Delta$ dotA-GFP were progressively cleared by $24 \mathrm{hpi}$. In contrast, some zebrafish larvae injected with HD of WT-GFP were unable to eliminate the bacteria at $72 \mathrm{hpi}$, and the bacterial burden even increased by $48-72 \mathrm{hpi}$ (Fig 1C). We also monitored infected larvae by fluorescent microscopy. Immediately upon injection (20 min to $2 \mathrm{hpi}$ ), bacteria were detectable as small foci, probably associated with professional phagocytes (Fig. 1D). By 24 hpi, in both, larvae injected with LD of WT-GFP as well as larvae injected with HD of the avirulent $\Delta$ dotA-GFP strain, the GFP signal declined becoming undetectable by $48 \mathrm{hpi}$, suggesting that the bacteria were progressively cleared. Despite showing the same pattern $24 \mathrm{hpi}$, larvae injected with HD of WT-GFP displayed a radically different progression of infection at $48 \mathrm{hpi}$, as bacterial proliferation started in a fraction of the infected larvae as seen by an increase in GFP signal. Most interestingly, in these larvae, bacterial proliferation occurred mainly in the yolk region while the bacterial load in the body decreased simultaneously. These bacterial foci in the yolk increased dramatically over time, causing death of the infected larvae by 72 hpi (Fig 1D).

Collectively our results indicate that $L$. pneumophila WT, but not the T4SS mutant induces phenotype, an increase of the bacterial burden in the yolk region. 
bioRxiv preprint doi: https://doi.org/10.1101/2021.10.18.464513; this version posted October $19,2021$. The copyright holder for this preprint (which was not certified by peer review) is the author/funder, who has granted bioRxiv a license to display the preprint in perpetuity. It is made available under aCC-BY-NC-ND 4.0 International license.

Bloodstream L. pneumophila establishes a proliferative niche in the yolk region causing a persistent infection

161 To characterise the L. pneumophila foci identified in the yolk region of zebrafish larvae, we used high

162 resolution fluorescent microscopy of HD of WT-GFP bloodstream injected in $72 \mathrm{hpf}$

$163 \operatorname{Tg}(m f a p 4:: m C h e r r y F)$ (herein referred as mfap4:mCherryF) (red macrophages) or $\operatorname{Tg}(L y z:: D s R e d)^{n 250}$

164 (herein referred as lyz:DsRed )(red neutrophils) or $\operatorname{Tg}(k d r l:: m C h e r r y)^{\text {is5 }}$ (red blood vessels) larvae.

165 Upon injection of HD of WT-GFP, bacteria were progressively eliminated by the rest of the body and

166 appeared growing in the yolk region between 48 and $72 \mathrm{hpi}$, with macrophages accumulating there

167 (Fig. 2A). We observed that L. pneumophila foci in the yolk region are highly complex, aggregate-like

168 structures of long, filamentous bacteria growing in the yolk cell region and not in the visceral organs

169 of the zebrafish larva. Macrophages were recruited to the yolk region containing L. pneumophila,

170 (Fig. 2B, D Movie S1). Similarly, upon injection of HD of WT-GFP in lyz:DsRed larvae (red neutrophils),

171 neutrophils were recruited to and accumulated around the growing bacterial aggregates, but seem

172 unable to engulf them (Fig 2E, Movie S2 ).Moreover, confocal microscopy revealed that $L$.

173 pneumophila exhibits grow in aggregates, and that these growing complex bacterial structures

174 localize in the yolk and or in the yolk tube (Fig. 2F, Movie S3 ). Upon injection HD of WT-GFP in

$175 \operatorname{Tg}(k d r l:: m C h e r r y)^{i s 5}$ (red blood vessels) larvae, we also showed that, the fast growing bacterial

176 aggregates interact with the blood vessels (Fig 2G, Movie S4). It should be noted that the yolk is the

177 only food source of the larvae during this developmental stage. The fast proliferation of the bacteria

178 in the yolk region probably depletes its nutritional content, leading to larvae death (Fig 2, Movie S1).

179 Strikingly, zebrafish larvae infected with the T4SS deficient $\Delta \operatorname{dotA}$ mutant strain, did neither develop

180 bacterial colonisation of the yolk nor larval death. This outcome was independent of the used dose,

181 suggesting that zebrafish susceptibility to L. pneumophila infection and yolk penetration depends on 182 a functional T4SS system.

183 Thus, blood-borne L. pneumophila is able to invade the yolk sac of zebrafish larvae, a

184 previously undescribed phenotype of bacterial infection in this model. Once in the yolk, the bacteria

185 replicate extensively, forming complex, organized, aggregate-like structures that cannot be removed

186 by macrophages and neutrophils, thereby avoiding he host's immune control and clearance,

187 eventually leading to death of the larvae.

189 Infection of zebrafish larvae with high doses of L. pneumophila leads to macrophage and 190 neutrophil death

191 In human infection, alveolar macrophages are the primary cell type infected by L. pneumophila

192 supporting its intracellular replication. Following infection, neutrophils are recruited to the lung and 193 are key players for controlling infection as they possess antimicrobial activity and kill L. pneumophila 
bioRxiv preprint doi: https://doi.org/10.1101/2021.10.18.464513; this version posted October 19, 2021. The copyright holder for this preprint (which was not certified by peer review) is the author/funder, who has granted bioRxiv a license to display the preprint in perpetuity. It is made available under aCC-BY-NC-ND 4.0 International license.

$194 \quad{ }^{24}$. To analyse whether zebrafish infection mirrors human infection we monitored the interaction of

195 zebrafish macrophages or neutrophils with the bacteria in vivo. The transgenic zebrafish larvae

196 mfap4:mCherryF and lyz:DsRed were injected with low or high doses of WT-GFP or with high doses of

$197 \Delta$ dotA-GFP. Infected larvae were monitored using widefield fluorescence microscopy and the

198 number of leukocytes per larva was assessed by counting fluorescent macrophages and neutrophils

199 over time until 72hpi. We observed that upon injection of high dose WT-GFP, the macrophage count

200 decreased dramatically at 24hpi and then remained stable (Fig. 3A, B). Neutrophil counts gave similar

201 results, as there was a dramatic decrease observed in neutrophil numbers starting at $24 \mathrm{hpi}$, in

202 particular after injection of high doses of WT bacteria Fig. 3C, D). Interestingly, upon infection with

203 low doses of WT the neutrophil numbers decreased dramatically only at 24hpi but increased at $48 \mathrm{hpi}$

204 and 72hpi (Fig. 3D). In contrast macrophage and neutrophil counts remained unaffected upon

205 injection of equal amounts of the avirulent $\Delta \operatorname{dot} A$ strain, suggesting that phagocyte death is linked to

206 a functional T4SS system.

207 Taken together, these results show that high dose L. pneumophila infection leads to a

208 decrease in the number of professional phagocytes dependent on the T4SS, similar to what is seen

209 during human infection by L. pneumophila and Mycobacterium tuberculosis ${ }^{24,25}$

Macrophages are the primary cells to phagocytise blood-borne L. pneumophila and neutrophils co-

\section{2 operate to decrease bacterial load}

213 As macrophages and neutrophils are likely the phagocytes that interact with L. pneumophila we

214 analysed phagocyte-L. pneumophila interactions in vivo by injecting mfap4:mCherryF or lyz:DsRed

$21572 \mathrm{hpf}$ larvae with WT-GFP or $\triangle$ dotA-GFP and recorded phagocyte-L. pneumophila interactions using

216 high resolution confocal microscopy. This showed that upon injection of LD WT-GFP, macrophages

217 immediately contacted and engulfed blood-borne bacteria, and the initial bacterial load was thereby

218 unchanged for 8hpi. The GFP signal of the engulfed bacteria was present for a long time in

219 macrophages, suggesting that live bacteria persist in macrophages in vivo over a certain period of

220 time. However, macrophages were continuously recruited to the site of infection and by 16hpi the

221 bacteria were mostly undetectable (Fig. 4A top panel, Movie S5). Macrophages that had engulfed a

222 large amount of L. pneumophila stopped moving and rounded-up, suggesting cell death. Similarly,

223 the inhibition of the migration of phagocytes by L. pneumophila has been observed previously during

224 infection of RAW 264.7 macrophages and the amoeba Dictyostelium discoideum and Acanthamoeba

225 castellanii, ${ }^{26,27}$. In contrast, zebrafish infected with HD of WT-GFP were not able to restrict the

226 bacterial growth by $16 \mathrm{hpi}$. HD of $L$ pneumophila formed big aggregates, that were not easily engulfed

227 and cleared by macrophages (Fig 4A, bottom panel, Movie S5). Remarkably, macrophages were very

228 efficient in engulfing and rapidly clearing high doses of blood-borne $\Delta$ dotA-GFP bacteria. By $10 h p i$ 
bioRxiv preprint doi: https://doi.org/10.1101/2021.10.18.464513; this version posted October 19, 2021. The copyright holder for this preprint (which was not certified by peer review) is the author/funder, who has granted bioRxiv a license to display the preprint in perpetuity. It is made available under aCC-BY-NC-ND 4.0 International license.

most of the bacteria had been engulfed and cleared as suggested by the diffuse GFP staining in phagocytes (Fig. 4A, bottom panel, Movie S5). However, upon infection with a HD WT-GFP, bacteria were not completely cleared but persisted, and at $72 \mathrm{hpi} \mathrm{L.} \mathrm{pneumophila} \mathrm{was} \mathrm{found} \mathrm{in} \mathrm{macrophages,}$ suggesting that the bacteria are also replicating in macrophages of zebrafish larvae. Indeed, high resolution confocal microscopy showed that at $72 \mathrm{hpi}$, L. pneumophila can also be found inside of macrophages in replicative vacuoles (Fig. S2).

The analyses of $L$. pneumophila-neutrophil interactions showed that these engulfed the bacteria trapped in the mesenchyme around the site of injection, but they were less efficient at clearing

238 blood-borne bacteria. This is similar to what has been previously observed for infection of zebrafish 239 larvae with Escherichia coli or Shigella flexneri ${ }^{22,28}$. Indeed, upon infection with a high dose of WT-

240 GFP, L. pneumophila persisted in neutrophils and massive death of infected neutrophils occurred

241 (Fig. 4B, second panel, Movies S6). In sharp contrast, neutrophils very efficiently engulfed and

242 cleared large amounts of $\triangle$ dotA-GFP aggregated and trapped in the mesenchyme (Fig. $4 \mathrm{~B}$, lower

243 panel, Movie S6) as well as low doses of WT-GFP (Fig 4B upper panel, Movie S6).

Altogether this shows that upon bloodstream injection of L. pneumophila, macrophages and neutrophils efficiently cooperate to eliminate the majority of bacteria within $20-24 \mathrm{hpi}$, with macrophages playing the primary role. However, L. pneumophila is also able to persist and replicate in macrophages. In contrast, neutrophils interact with L. pneumophila by quickly engulfing bacteria trapped in the mesenchyme near the site of injection but are less efficient in clearing blood-borne Macrophages are the first line defence restricting L. pneumophila infection

In humans, innate immune responses, based essentially on the activities of professional phagocytes and pro-inflammatory cytokine induction, are the key players to control and restrict L. pneumophila proliferation. Thus, human disease develops primarily in immunocompromised individuals ${ }^{10}$. To investigate whether the phagocytes of the innate immune system, macrophages and neutrophils, are

256 also responsible for controlling L. pneumophila infection in zebrafish larvae, we selectively and

257 transiently depleted macrophages or neutrophils, respectively and infected these

258 "immunocompromised" larvae with L. pneumophila. Depletion of macrophages was achieved by

259 knocking down the expression of spi1b, a transcription factor involved in early myeloid progenitor

260 formation. A low dose of spi1b morpholino was reported to impact macrophages without affecting

261 neutrophils ${ }^{29}$. We monitored the effect of low doses spi1b morpholino injection on macrophage and

262 neutrophil populations in double transgenic larvae with green neutrophils (mpx:GFP) and red 
bioRxiv preprint doi: https://doi.org/10.1101/2021.10.18.464513; this version posted October 19, 2021. The copyright holder for this preprint (which was not certified by peer review) is the author/funder, who has granted bioRxiv a license to display the preprint in perpetuity. It is made available under aCC-BY-NC-ND 4.0 International license.

macrophages (mfap4:mCherryF). The specific depletion of the two cell types was confirmed by counting macrophages and neutrophils $72 \mathrm{hpf}$ (Fig S3A).

We then infected macrophage depleted larvae (spi1b knockdown) by intravenous injection of LD or HD of WT-GFP. Independently of the infection dose, a dramatic decrease in survival occurred, as even injection of low doses of WT-GFP resulted in the death of $30 \%$ of the larvae (Fig 5A). When injecting high doses of WT-GFP nearly all of the infected larvae died by $72 \mathrm{hpi}$, with the earliest deaths starting 48hpi (Fig 5A). In contrast, spilb knockdown larvae injected with high doses of $\triangle$ dotAGFP did not show impaired survival (Fig 5A). The increased mortality correlated with an increased bacterial burden in spi1b knockdown larvae compared to control larvae as judged from counting bacteria growing on BCYE agar from homogenates of individual larvae by FACS analyses (Fig 5B). Intravital imaging of infected spi1b knock down larvae also showed that both low and high doses of WT-GFP failed to be cleared and that the bacteria established a replicative niche in the yolk, where they proliferated extensively (Fig $5 \mathrm{C}$ ). This highlights, that macrophages are critical to restrict the onset of infection and L. pneumophila proliferation in vivo. Furthermore, these results also suggest that neutrophils, which are not depleted in spi1b knockdown larvae, fail to control L. pneumophila infection in the absence of macrophages.

We next analysed the role of neutrophils in controlling the infection. Neutrophil

280 development was disrupted by knocking down the G-CSF/GCSFR pathway using csf3R morpholino, 281 previously reported to decrease up to $70 \%$ of the neutrophils present ${ }^{30-32}$. We then monitored the 282 efficiency of the $c s f 3 R$ morpholino knockdown in double transgenic larvae confirming that $75 \%$ of the 283 neutrophil population was depleted, while macrophage numbers were only slightly decreased (Fig 284 S3B). When HD $\triangle$ dotA-GFP was injected, neutrophil-depleted larvae survived, and the bacterial burden remained unchanged, similar to what we had observed in infections of macrophage-depleted larvae (Fig. 5D, E). However, when neutrophil-depleted larvae were injected with HD WT-GFP, larvae survival significantly decreased and bacterial burdens increased at 48hpi (Fig. 5D, E). Neutrophildepleted fish larvae showed an intermediate phenotype, displaying less survival and higher bacterial burden than in WT infected control larvae (Fig. 1A) but more survival and lower bacterial burden than in macrophage-depleted larvae (Fig. 5D, E). Intravital imaging showed that csf3R knockdown

291 larvae that were unable to control L. pneumophila infection showed bacterial proliferation in the yolk 292 comparable to WT control larvae (Fig 5F).

293 These results show that both neutrophils and macrophages are required for restricting and 294 controlling L. pneumophila infection in the zebrafish model, but macrophages play the key role. 295 Although neutrophils contributed less to clear the bacteria upon bloodstream injection, neutrophils 296 might impact the infection outcome through cytokine release that can modulate macrophage 297 activity. 
bioRxiv preprint doi: https://doi.org/10.1101/2021.10.18.464513; this version posted October 19, 2021. The copyright holder for this preprint (which was not certified by peer review) is the author/funder, who has granted bioRxiv a license to display the preprint in perpetuity. It is made available under aCC-BY-NC-ND 4.0 International license.

Key pro-inflammatory cytokines are induced upon L. pneumophila infection of zebrafish larvae

299 Proinflammatory cytokines produced by infected and bystander cells during L. pneumophila infection

300 of humans and mice play crucial roles in orchestrating host defences to control infection ${ }^{33,34}$.

301 Infected cells produce IL-1 $\alpha$ and IL-1 $\beta$ through a mechanism involving MyD88-dependent translational bypass. In contrast, bystander cells produce IL-6, TNF- $\alpha$ and IL-12 in an IL-1 receptor (IL1R) dependant way ${ }^{33,35}$. To determine the pro-inflammatory responses of zebrafish larvae during $L$. pneumophila infection, we analysed il1b, tnfa, and ifng1/2 (orthologues of mammalian Ifng) gene expression levels over time by qRT-PCR on RNA isolated from individual infected larvae. We found that infection of zebrafish larvae with LD or HD of WT-GFP induced a rapid (by 6hpi) and robust induction of $i l 1 b$ and tnfa gene expression. In larvae injected with low doses of WT-GFP the expression levels started to decrease by $24 \mathrm{hpi}$, and gradually became undetectable at $72 \mathrm{hpi}$. In contrast, larvae injected with HD of WT-GFP, expression of $i l 1 b$ and tnfa did not decrease over time (Fig. S3A and B) and a significant induction of ifng1 was observed at 48hpi (Fig. S3C) but not of ifng2 (Fig. S3D). In parallel, we scored the bacterial burden of the infected larvae before pro-inflammatory cytokine measurement at each time point under the microscope, which consistently showed that larvae with increased $i l 1 b$ and tnfa induction had also high bacterial burdens in the yolk and were not controlling the infection. These pro-inflammatory responses were T4SS dependent, as zebrafish larvae infected with HD of $\Delta$ dotA-GFP did not show significant induction of transcription of tnfa, il1b and ing1/2 (Fig. S3 A-D).

Collectively, these results reveal, that key pro-inflammatory cytokines known to orchestrate the host response during L. pneumophila infection in humans are also induced in zebrafish larvae, and that cytokine gene induction is sustained when uncontrolled L. pneumophila proliferation occurs.

The immune response of zebrafish larvae to L. pneumophila infection is independent of MyD88

323 In innate immunity, the myeloid differentiation factor 88 (MyD88) plays a pivotal role in immune cell

324 activation through Toll-like receptors (TLRs). MyD88-deficient mice are highly susceptible to

325 L. pneumophila infection ${ }^{36-39}$, however this is not the case when human macrophages are depleted

326 of MyD88 ${ }^{40}$. Therefore, we sought to analyse which role MyD88 plays in zebrafish larvae during

327 L. pneumophila infection. We injected myd88-/- and control larvae with LD or HD of WT-GFP, or with

328 HD of $\triangle$ dotA-GFP and monitored larvae survival and bacterial burden over time as described in Figure

329 1. Our results show that susceptibility to infection of myd88-/- larvae injected with HD of WT-GFP,

330 was comparable to that of WT larvae (Fig. 6A). Similarly, both control and myd88-/- larvae injected

331 with LD WT-GFP or with the avirulent $\triangle$ dotA-GFP bacteria did not develop an infection, and the 
bioRxiv preprint doi: https://doi.org/10.1101/2021.10.18.464513; this version posted October $19,2021$. The copyright holder for this preprint (which was not certified by peer review) is the author/funder, who has granted bioRxiv a license to display the preprint in perpetuity. It is made available under aCC-BY-NC-ND 4.0 International license.

332 bacterial burden decreased over time indicating that bacteria were cleared (Fig. 6A, B). To determine

333 if pro-inflammatory responses were affected in the absence of MyD88 signalling, we analysed il1 $b$

334 and tnfa gene expression levels over time in control and myd88-/- larvae. Our results showed that

335 il1b and tnfa gene expression levels were comparable in control and myd88-/- infected larvae for all conditions tested (LD WT-GFP and HD $\Delta \operatorname{dotA-GFP~(Fig~6C,~D).~}$

Taken together, our results suggest that MyD88 signalling is not required for the innate immune response against $L$. pneumophila infection in the zebrafish larvae, which recapitulates human infection. However, MyD88 signalling may also be functionally compensated by other immune signalling pathways.

\section{Legionella pneumophila replication in the yolk of zebrafish larvae is T4SS dependent}

343 Interestingly, replication of L. pneumophila mainly took place in the yolk region of infected zebrafish

344 larvae (Movie S1-4, Fig. 2), dependent on a functioning T4SS as $\Delta \operatorname{dotA}$-GFP failed be detected in the

345 yolk. To investigate whether the secretion mutant would be able to grow in the yolk cell when

346 reaching it, we injected LD and HD of WT-GFP or $\triangle$ dotA-GFP directly into the yolk cell cytoplasm of

347 72hpf lys:DsRed zebrafish larvae (Fig. S4A). WT-GFP replicated extensively in the yolk region with low

348 and high dose infections leading to rapid bacterial proliferation followed by a marked increase of the

349 bacterial burden and death of the larvae (Fig. 7A, B). Surprisingly, $\triangle$ dotA-GFP did not replicate in the

350 yolk even when injected directly but persisted over $72 \mathrm{hpi}$. This result suggests that T4SS system is

351 not only crucial for crossing the yolk sac syncytium but that its effectors are also necessary to obtain

352 nutrients from the environment to allow replication. To further analyze this hypothesis, we selected

353 a mutant in the gene encoding a sphingosine-1 phosphate lyase, (WT, $\Delta s p l)^{41}$ as we reasoned that

354 this enzyme might be implicated in degrading sphingolipids present in the yolk of zebrafish larvae and thereby might aid L. pneumophila to obtain nutrients. Injection of $\Delta s p /$ in the yolk sac region, and analyses of larvae death as compared to WT or $\Delta \operatorname{dot} A$ showed that survival of zebrafish larvae injected with the $\Delta s p /$ was slightly higher than with WT injected larvae (Fig. S4B), suggesting that the T4SS effector $L p S p l$ might be implicated in nutrient acquisition in the yolk environment.

Interestingly, the first isolation of L. pneumophila was achieved by inoculating the yolk region

360 of embryonated eggs probably due to the richness in nutrients provided by the yolk ${ }^{6}$. Later yolk sacs

361 of embryonated hen's eggs were used to produce polyvalent antigens for the diagnosis of

362 L. pneumophila ${ }^{42}$. Thus, we decided to analyse L. pneumophila WT and $\Delta \operatorname{dotA}$ phenotypes in the yolk 363 sac of embryonated chicken eggs (ECE). We inoculated ECE directly in the yolk region with WT and 364 with the $\triangle \operatorname{dot} A$ strain at a concentration of $9.2 \log _{10} \mathrm{CFU} / \mathrm{mL}$ and $9.1 \log _{10} \mathrm{CFU} / \mathrm{mL}$, respectively and 365 assessed mortality of the embryos daily. The total mortality during the 6-day observation period in 366 WT-GFP infected eggs was significantly higher (88.9\%) than in the $\Delta$ dotA-infected eggs (14.3\%; 
bioRxiv preprint doi: https://doi.org/10.1101/2021.10.18.464513; this version posted October 19, 2021. The copyright holder for this preprint (which was not certified by peer review) is the author/funder, who has granted bioRxiv a license to display the preprint in perpetuity. It is made available under aCC-BY-NC-ND 4.0 International license.

$p=0.010)$ or PBS inoculated control eggs ( $28.6 \% ; p=0.010$ and $p=0.021$, respectively), which were not significantly different from each other $(p=0.253)$ (Fig. S4C). The highest mortality was observed at 2 days post infection in WT inoculated eggs with $55.6 \%$ mortality versus $0 \%$ in $\Delta$ dotA or $28.6 \%$ mortality in PBS inoculated eggs. Quantification of L. pneumophila in the yolk sac region at the day of mortality or at day 6 post infection revealed that the number of bacteria in the yolk sac of WTinfected ECE, was significantly higher than that in the yolk sac of those infected with the $\triangle \operatorname{dot} A$ strain (7.8 $\log _{10} \mathrm{CFU} / \mathrm{mL}$ and $5.9 \log _{10} \mathrm{CFU} / \mathrm{mL}$, respectively, $\mathrm{p}=0.0127$ ) (Fig. S4D). Controls inoculated with PBS $(n=2)$ showed no L. pneumophila growth. Thus, like in zebrafish larvae only the WT strain is able to replicate in the yolk region and of inducing mortality in the embryos, while the T4SS mutant strain persists but is not able to replicate and does not induce high embryo mortality. This result further supports the finding that the T4SS system is crucial for obtaining nutrients when lipids are the major energy source available.

We next monitored neutrophil behaviour in the yolk-injected lyz:DsRed larvae in which neutrophils are labelled red. This showed that replication of WT-GFP in the yolk coincides with neutrophil death (Fig. 7C and D). The yolk cell is a single large cell where leukocytes were described to be unable to enter ${ }^{43}$, but interestingly, macrophages and neutrophils were highly recruited to the yolk of WT-GFP infected larvae (Figure 2B-E), suggesting that L. pneumophila is sensed by the immune system even when replicating in the yolk, and could induce neutrophil death "at distance". It is likely neutrophils can partly counteract $L$. pneumophila growth in the yolk by degranulating "at distance", as previously shown in a zebrafish notochord infection model using non-pathogenic $E$. coli 32.

Our results suggest that the L. pneumophila T4SS plays a crucial role for the bacteria to pass from the blood circulation into the yolk and that T4SS effectors play an important role to obtain nutrients for bacterial proliferation.

\section{DISCUSSION}

393 In this study, we developed a zebrafish larva infection model for L. pneumophila and have analysed

394 host pathogen interactions and the innate immune response of the host. We have found that a

395 successful infection of zebrafish larvae by L. pneumophila depends on the infection site, the infection

396 dose, the T4SS Dot/Icm and the host innate immune response, in particular macrophages and

397 neutrophils. Wild type zebrafish larvae are susceptible to infection in a dose dependent manner, as

398 larvae infected with a highly concentrated bacterial inoculum displayed bacterial dissemination and

399 replication, concomitant with host death. However, as only about $30 \%$ of the larvae displayed this

400 phenotype, the innate host defence of the larvae against L. pneumophila infection is relatively

401 efficient. Thus, similar to what is observed in L. pneumophila infection of immune competent 
bioRxiv preprint doi: https://doi.org/10.1101/2021.10.18.464513; this version posted October $19,2021$. The copyright holder for this preprint (which was not certified by peer review) is the author/funder, who has granted bioRxiv a license to display the preprint in perpetuity. It is made available under aCC-BY-NC-ND 4.0 International license.

402 individuals, the development of Legionnaire's disease is determined not only by the infection dose

403 but also by the capacity of the host immune system to quickly and efficiently respond to infection.

404 Only blood borne bacteria are able to proliferate and induce mortality in zebrafish larvae.

405 Once in the blood circulation, bacteria are actively engulfed and eliminated by both macrophages

406 and neutrophils. However, some bacteria resist intracellular killing and replicate extensively inside

407 macrophages (Fig. S2), get released into the blood flow and circulate in the zebrafish larvae. Some

408 reach the yolk sac syncytium and T4SS competent L. pneumophila are able to cross this barrier and

409 enter the yolk sac region. Once in the yolk, L. pneumophila gains a significant advantage in the

410 pathogen-host arms race and establishes a replicative niche where it proliferates extensively. Indeed,

411 in the yolk sac region L. pneumophila is protected from the host immune system as professional

412 phagocytes are unable to enter in the yolk. Proliferation of the bacteria leads to host death, likely

413 due to exhaustion of the nutrients present in the yolk, which are key in supporting the larvae

414 development and due to the physical compression of the visceral developing organs, in particular the

415 gastro-intestinal tract, exerted by the growing bacterial aggregate. Interestingly, we have also

416 observed that in few cases the infected larvae were able to extrude the bacterial aggregates growing

417 in the yolk and survived. This host defence mechanism has also been reported in a caudal fin model

418 of Mycobacterium marinum infection, where infected zebrafish larvae extruded the bacteria-

419 containing granuloma ${ }^{44}$.

420 To our knowledge, the establishment of a replicative niche in the yolk upon injection in the 421 bloodstream is unique to L. pneumophila. Most interestingly, direct yolk sac injection revealed that 422 only the WT strain but not the T4SS knockout strain is able to replicate and establish a persistent 423 infection, irrespective of the dose injected. This result points towards the involvement of the T4SS

424 system and its secreted effectors in infection, replication and nutrient uptake in the yolk

425 environment. Further analyses of this phenotype in embryonated chicken eggs, a commonly used

426 model for antigen preparation, showed again, that only WT L. pneumophila are able to replicate in

427 the yolk sac region, confirming the importance of the T4SS in nutrient uptake in addition to its known

428 role in infection (Fig. S4A, B, C). L. pneumophila is known to mainly use amino acids as carbon and

429 energy sources for growth ${ }^{45}$ and secreted T4SS effectors have been shown to aid in amino acid

430 uptake ${ }^{46}$, however, fatty acids, glucose and/or glycerol also serve as carbon sources during the later

431 stages of the life cycle of $L$. pneumophila ${ }^{47,48}$, but no effectors connected to the uptake of these

432 nutrients have been identified yet. The yolk cell is composed of a complex and dynamic mixture of

433 different lipids on which the zebrafish larvae rely on for nutrition throughout development in the

434 early larva phase. Cholesterol and phosphatidylcholine are the main constituents until 120hpf, with

435 triacylglycerol, phosphatidylinositol, phosphatidylethanolamine, diacyl-glycerol, cholesteryl esters

436 and sphingomyelins also present in significant concentrations ${ }^{49}$. L. pneumophila is known to secrete 
bioRxiv preprint doi: https://doi.org/10.1101/2021.10.18.464513; this version posted October 19, 2021. The copyright holder for this preprint (which was not certified by peer review) is the author/funder, who has granted bioRxiv a license to display the preprint in perpetuity. It is made available under aCC-BY-NC-ND 4.0 International license.

several effectors with lipolytic activity through its T4SS which could be important for growth in a lipid rich environment like the yolk (Hiller et al., 2018). In a first attempt to identify one of these effectors we analysed the growth of a L. pneumophila mutant in a gene encoding a sphingosine-1 phosphate lyase (LpSpl) ${ }^{41}$ compared to the WT strain after direct injection in the zebrafish larvae yolk sac. Indeed, a small difference in larvae mortality was observed for the $\Delta s p /$ strain, suggesting that $L p S p l$ is one of several effectors that might participate in nutrient acquisition from lipids (Fig. S4B). However, further analyses are needed to identify all effectors implicated in this phenotype.

Studies of Legionella infection in humans, guinea pigs and mouse lungs have shown that L. pneumophila interacts closely with neutrophils and mononuclear phagocytes ${ }^{50,51}$. Professional phagocytes are the main replication niche for $L$. pneumophila with monocytes and macrophages, in particular alveolar macrophages, representing the main cells for replication in the lungs ${ }^{52-55}$. In vivo studies in mice have shown that upon lung infection with L. pneumophila neutrophils, cDCs, monocytes, and monocyte-like cells are rapidly recruited to the infection site, but although all these cells seem to engulf the bacteria, L. pneumophila appears to be able to translocate effectors only into neutrophils and alveolar macrophages. In zebrafish macrophages appear during the first days of development, followed by neutrophils a day later forming together an efficient immune system that protects the developing fish ${ }^{23,56-58}$. Therefore, the zebrafish larva offers a unique possibility to interrogate the role of innate immune responses to infection ${ }^{21}$. Indeed, macrophage depleted larvae showed a dramatically increased susceptibility to L. pneumophila infection as nearly $100 \%$ of larvae inoculated with HD of WT and $30 \%$ of larvae inoculated with LD of $L$. pneumophila died from the infection. Hence, macrophages are the first line of infection control against $L$. pneumophila and are essential for restricting and controlling blood-borne infections, similar to what was observed for Burkholderia cenocepacia or Staphylococcus aureus infection ${ }^{59,60}$. In contrast, when neutrophils were depleted, the innate immune response was impaired to a lesser extent, suggesting that neutrophils are required to ensure an effective innate immune response and, that macrophages alone are not able to contain high burdens of L. pneumophila infection (Fig. 5).

Human innate immune signalling relies strongly on activation of Toll-like receptors (TLRs) and respective adaptor molecules, all of which are highly conserved in the zebrafish ${ }^{61,62}$. One of these adaptors is MyD88, known as a central player in interleukin 1 receptor (IL-1R) and TLR signalling in humans and mammalian models ${ }^{63}$. MyD88 signalling is crucial for mice to combat L. pneumophila infection, as it triggers the early secretion of inflammatory cytokines, neutrophil recruitment, and the host immune response to the infection. Consequently, mice that lack MyD88 are highly susceptible to infection ${ }^{35-38}$. However, in MyD88 depleted human macrophages L. pneumophila replication is not different to replication in WT cells ${ }^{40}$ Here we show, that L. pneumophila infected myd88-/- zebrafish larvae have the same replication phenotype as WT larvae. Thus, Myd88 signalling does not play a key 
bioRxiv preprint doi: https://doi.org/10.1101/2021.10.18.464513; this version posted October 19, 2021. The copyright holder for this preprint (which was not certified by peer review) is the author/funder, who has granted bioRxiv a license to display the preprint in perpetuity. It is made available under aCC-BY-NC-ND 4.0 International license.

472 role or may be redundant in the control of the innate immune response to L. pneumophila in

473 zebrafish larvae, indicating that zebrafish mirrors human infection better than the mouse model. In

474 the mouse model infected macrophages are incapable of producing cytokines, such as tumor

475 necrosis factor (TNF) and interleukin-12 (IL-12), which are necessary to control infection. In contrast,

476 infection of zebrafish larvae with WT L. pneumophila induced a rapid (by 6hpi) and robust induction

477 of $i l 1 b$ and tnfa gene expression. However, it is thought that IL-1 released initially by L. pneumophila-

478 infected macrophages drives the production of critical cytokines by bystander cells ${ }^{33}$. Infection of

479 zebrafish larvae with HD of WT L. pneumophila induced a rapid (by 6hpi) and robust induction of il1b

480 and tnfa gene expression whereas WT LD infection leads only to a short induction of $/ / 1 \mathrm{~b}$ transcript

481 levels at 6hpi before declining to CTRL levels at later time points, suggesting that a short boost of IL-

$4821 \beta$ is sufficient to control LD of L. pneumophila. However, for a high load of $L$. pneumophila even a

483 high and long-term induction of IL-1 $\beta$ is not allowing to control the infection, suggesting that the self-

484 regulation of the immune response may be abrogated leading to a constant activation of IL-1 $\beta$

485 expression. Moreover, gene expression analyses also confirms that Myd88 has no influence on the

486 control of the infection, as no difference in the transcript levels of $i l 1 b$, tnfa, ifng1 or infg 2 was

487 observed further suggesting that activation of the IL1R and certain TLR pathways are not crucial for

488 L. pneumophila clearance in zebrafish larvae. One may even hypothesise that IL-1ß release could be

489 beneficial for $L$. pneumophila replication, as it was shown that IL-1 $\beta$ also may indicate an activation of

490 the metabolic state of the bystander cells as it was shown that IL-1 $\beta$ induces a shift towards more

491 metabolically active cells and increased cellular glucose uptake ${ }^{64}$, which could aid L. pneumophila

492 replication.

493 In conclusion, we have set up a new infection model for L. pneumophila that mimics human

494 infection better than the mouse model. The unique advantages of the zebrafish provide now exciting

495 possibilities to further explore different aspects of the relationship between, L. pneumophila and its

496 host: the dynamics of bacterial dissemination, the interactions of the bacteria with macrophages and

497 neutrophils, as well as the host immune response by intravital imaging.

499 EXPERIMENTAL PROCEDURES

500 Ethics Statement. Animal experiments were performed according to European Union guidelines for

501 handling of laboratory animals

502 ((http://ec.europa.eu/environment/chemicals/lab animals/home en.htm) and were approved by

503 the Institut Pasteur Animal Care and Use Committee. and the French Ministry of Research

504 (APAFIS\#31827). The inoculation of embryonated chicken eggs is a standard procedure in diagnostics

505 for the multiplication and antigen production of Legionella and is not covered by the national law for

506 animal experiments in France (Décret $n^{\circ}$ 2013-118 du 1er février 2013). 
bioRxiv preprint doi: $\mathrm{https://doi.org/10.1101/2021.10.18.464513;} \mathrm{this} \mathrm{version} \mathrm{posted} \mathrm{October} \mathrm{19,} \mathrm{2021.} \mathrm{The} \mathrm{copyright} \mathrm{holder} \mathrm{for} \mathrm{this}$ preprint (which was not certified by peer review) is the author/funder, who has granted bioRxiv a license to display the preprint in perpetuity. It is made available under aCC-BY-NC-ND 4.0 International license.

Zebrafish care and maintenance. Wild-type $A B$ fish, initially obtained from the Zebrafish International Resource Center (Eugene, OR), $\operatorname{Tg}(L y z:: D s R e d)^{\text {nz50 }}{ }^{55}, \operatorname{Tg}(m f a p 4:: m C h e r r y F)(u m p 6 \operatorname{Tg})^{32}$

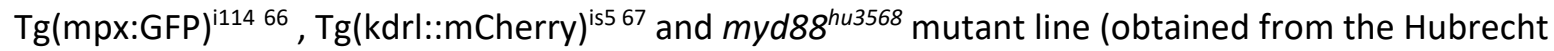

510 Laboratory and the Sanger Institute Zebrafish Mutation Resource) ${ }^{68}$, were raised in our facility. Eggs were obtained by natural spawning, bleached according to standard protocols, and kept in Petri dishes containing Volvic source water and, from 24 hours post fertilization (hpf) onwards $0.003 \% 1$ phenyl-2-thiourea (PTU) (Sigma-Aldrich) was added to prevent pigmentation. Embryos were reared at $28^{\circ} \mathrm{C}$ or $24^{\circ} \mathrm{C}$ according to the desired speed of development; infected larvae were kept at $28^{\circ} \mathrm{C}$. Timings in the text refer to the developmental stage at the reference temperature of $28.5^{\circ} \mathrm{C}$. Larvae were anesthetized with $200 \mu \mathrm{g} / \mathrm{ml}$ tricaine (Sigma-Aldrich) during the injection procedure as well as during in vivo imaging and processing for bacterial burden evaluation or cytokine expression studies.

Bacterial strains and growth conditions. Legionella pneumophila strain Paris carrying the pNT28 plasmid encoding for green fluorescent protein (constitutive GFP) ${ }^{69}$, wild-type (WT-GFP) or $\triangle$ dotAGFP were plated from $-80^{\circ} \mathrm{C}$ glycerol stocks on $\mathrm{N}$-(2-acetamido)-2-aminoethanesulfonic acid (ACES)buffered charcoal yeast-extract (BCYE) medium supplemented with $10 \mu \mathrm{g} / \mathrm{ml}$ of chloramphenicol and cultured for 3 days at $37^{\circ} \mathrm{C}$. Suspensions were prepared by resuspending bacteria in sterile $1 \mathrm{x}$ Phosphate Buffered Saline (PBS) and adjusting the OD 600 according to the desired bacterial concentrations for injection.

Morpholino injections. Morpholino antisense oligonucleotides (Gene Tools LLC, Philomath, OR, USA) were injected at the one to two cell stage as described ${ }^{70} \mathrm{~A}$ low dose $(4 \mathrm{ng})$ of spilb (previously named pu1) translation blocking morpholino (GATATACTGATACTCCATTGGTGGT) ${ }^{71}$ blocks macrophage development only, but can also block neutrophil development when it is injected at a higher dose (20ng in 2nl). The csf3r translation blocking morpholino (GAACTGGCGGATCTGTAAAGACAAA) (4ng) ${ }^{30}$ was injected to block neutrophil development. Control morphants were injected with 4 ng control morpholino, with no known target (GAAAGCATGGCATCTGGATCATCGA).

Zebrafish infections. The volume of injected suspension was deduced from the diameter of the drop

536 obtained after mock microinjection, as described in ${ }^{70}$. Bacteria were recovered by centrifugation,

537 washed, resuspended at the desired concentration in PBS. 72h post-fertilization (hpf) anesthetized

538 zebrafish larvae were microinjected iv or in the yolk with $0.5-1 \mathrm{nl}$ of bacterial suspension at the

539 desired dose ( $10^{3}$ bacteria/nl for Low Dose (LD) and $\sim 10^{4}$ bacteria/nl for High Dose (HD) as

540 described ${ }^{22,28}$. Infected larvae were transferred into individual wells (containing $1 \mathrm{ml}$ of Volvic water + 
bioRxiv preprint doi: https://doi.org/10.1101/2021.10.18.464513; this version posted October 19, 2021. The copyright holder for this preprint (which was not certified by peer review) is the author/funder, who has granted bioRxiv a license to display the preprint in perpetuity. It is made available under aCC-BY-NC-ND 4.0 International license.

$5410.003 \%$ PTU in 24-well culture plates), incubated at $28^{\circ} \mathrm{C}$ and regularly observed under a

542 stereomicroscope.

Evaluation of the bacterial burden in infected larvae. Infected zebrafish larvae were collected at 0 , 24, 48 and 72hpi and lysed for analysing the bacterial burden by FACS. Each larva was placed in a 1.5 $\mathrm{ml}$ Eppendorf tube and anesthetized with tricaine $(200 \mu \mathrm{g} / \mathrm{ml})$, washed with $1 \mathrm{ml}$ of sterile water and placed in $150 \mu \mathrm{l}$ of sterile water. Larvae were then homogenized using a pestle motor mixer (Argos). Each sample was transferred to an individual well of a 96 well plate, counted on a MACSQuant VYB FACS (Miltenyi Biotec) and data analysed using FlowJo version 7.6.5. For CFU enumeration, serial dilutions were plated on BCYE agar plates supplemented with Chloramphenicol and the Legionella Selective Supplement GVPN (Sigma). Plates were incubated for $4-5$ days at $37^{\circ} \mathrm{C}$ and colonies with the appropriate morphology and colour were scored using the G-Box imaging system (Syngene) and colonies enumerated using the Gene Tools software (Syngene).

Dissociation of zebrafish larvae for FACS analysis of macrophages. Three to five $\mathrm{Tg}$ (mfap4::mCherryF) larvae were pooled in single $1.5 \mathrm{ml}$ Eppendorf tubes and anesthetized with tricaine. The supernatant was discarded, and the larvae were resuspended in $1 \mathrm{ml}$ of $1 \mathrm{x}$ trypsin-EDTA solution (SIGMA) and incubated in a dry heat block at $30^{\circ} \mathrm{C}$ for $10-20$ min. Every 2 minutes, the suspensions were homogenised by pipetting, until full homogenisation was reached. $\mathrm{CaCl}_{2}$ (final concentration of $2 \mu \mathrm{M}$ ) and foetal bovine serum (final concentration of $10 \%$ ) were added to each tube and samples were kept on ice. Lysates were filtered using $40 \mu \mathrm{m}$ strainers, washed with $20 \mathrm{ml}$ ice cold $1 \mathrm{X}$ PBS and centrifuged $5 \mathrm{~min}$ at $1500 \mathrm{~g}, 4^{\circ} \mathrm{C}$. Remaining pellets were resuspended in $250 \mu \mathrm{l}$ 1X PBS and analysed with a MACSQuant VYB FACS (Miltenyi Biotec).

Live imaging, image processing and analysis. Quantification of total neutrophils and/or macrophages

566 on living transgenic reporter larvae was performed upon infection as previously described ${ }^{28}$. Briefly,

567 bright field, DsRed and GFP images of whole living anesthetized larvae were taken using a Leica

568 Macrofluo $^{\text {TM }}$ Z16 APOA (zoom 16:1) equipped with a Leica PlanApo 2.0X lens, and a Photometrics ${ }^{\circledR}$

569 CoolSNAP ${ }^{\mathrm{TM}}$ HQ2 camera. Images were captured using Metavue software 7.5.6.0 (MDS Analytical

570 Technologies). Then larvae were washed and transferred in a new 24 wells plate filled with $1 \mathrm{ml}$ of

571 fresh water per well, incubated at $28^{\circ} \mathrm{C}$ and imaged again under the same conditions the day after.

572 Pictures were analysed, and $\operatorname{Tg}(/ y z C:: D s R e d)$ neutrophils or $\operatorname{Tg}(m f a p 4:: m C h e r r y F)$ macrophages

573 manually counted using the ImageJ software (V 1.52a). Counts shown in figures are numbers of cells 574 perimage. 
bioRxiv preprint doi: https://doi.org/10.1101/2021.10.18.464513; this version posted October 19, 2021. The copyright holder for this preprint (which was not certified by peer review) is the author/funder, who has granted bioRxiv a license to display the preprint in perpetuity. It is made available under aCC-BY-NC-ND 4.0 International license.

The bacterial burden was measured by counting the total number of pixels corresponding to the GFP channel (Metavue software 7.5.6.0). Briefly, images corresponding to the GFP channel were adjusted to a fixed threshold that allowed to abrogate the background of the autofluorescence of the yolk. The same threshold was used for all images of one experiment. Histogram in the Analyze menu was used to obtain the number of black and white pixels. As shown in figure S1A, number of white pixels corresponding to L. pneumophila are plotted using GraphPad Prism ${ }^{\circledR}$ software. described ${ }^{72}$. Briefly, injected larvae were positioned in lateral or ventral position in $35 \mathrm{~mm}$ glassbottom-Dishes (Ibidi Cat\#: 81158). Larvae were immobilized using a 1\% low-melting-point agarose (Promega; Cat\#: V2111) solution and covered with Volvic water containing tricaine. A Leica SP8 confocal microscope equipped with two PMT and Hybrid detector, a 20X IMM objective (HC PL APO CS2 20X/0.75), a X-Y motorized stage and with the LAS-X software was used to live image injected larvae. To generate images of the whole larvae, a mosaic of confocal z-stack of images was taken with the 20X objective using the Tile Scan tool of the LAS-X software and was stitched together using the Mosaic Merge tool of the LAS-X software. All samples were acquired using the same settings, allowing comparisons of independent experiments. After acquisition, larvae were washed and transferred in a new 24 -well plate filled with $1 \mathrm{ml}$ of fresh water per well, incubated at $28^{\circ} \mathrm{C}$ and imaged again under the same conditions over time. A Leica SPE inverted confocal microscope and a

$59340 x$ oil immersion oil immersion objective (ACS APO $40 \times 1.15$ UV) was also used to live image larvae infected with L. pneumophila $\triangle \operatorname{dotA-GFP~(Figure~4).~}$

The 4D files generated by the time-lapse acquisitions were processed, cropped, analysed, and annotated using the LAS-X and LAS-AF Leica software. Acquired Z-stacks were projected using maximum intensity projection and exported as AVI files. Frames were captured from the AVI files and handled with Photoshop software to mount figures. AVI files were also cropped and annotated with ImageJ software. Files generated with the LAS-X software were also processed and analysed with the Imaris software version9.5 (Bitplane, OXFORD Instruments) for 3D reconstruction, surfacing and volume rendering.

qRT-PCR to measure gene expression of cytokine encoding genes. RNA was extracted from

604 individual larvae using the RNeasy ${ }^{\circledR}$ Mini Kit (Qiagen). cDNA was obtained using M-MLV H- reversetranscriptase (Promega) with a dT17 primer. Quantitative PCR was performed on an ABI7300

606 thermocycler (Applied Biosystems) using TakyonTM ROX SYBR ${ }^{\circledR}$ 2X MasterMix (Eurogentec) in a final volume of $10 \mu \mathrm{l}$. Primers used: ef1a (housekeeping gene used for normalization): 
bioRxiv preprint doi: https://doi.org/10.1101/2021.10.18.464513; this version posted October $19,2021$. The copyright holder for this preprint (which was not certified by peer review) is the author/funder, who has granted bioRxiv a license to display the preprint in perpetuity. It is made available under aCC-BY-NC-ND 4.0 International license.

613 Statistical analysis. Normal distributions were analysed with the Kolmogorov-Smirnov and the

614 Shapiro-Wilk tests. To evaluate difference between means of normally distributed data (for

615 neutrophil and macrophage numbers), an analysis of variance followed by Bonferroni's multiple

616 comparison tests was used. For bacterial burdens (CFU/FACS counts), values were Log10

617 transformed. Values of FACS and CFU counts did not pass the normality test, data were analysed

618 following the Mann-Whitney test. For cytokine expression and bacterial burdens, non-Gaussian data

619 were analysed with the Kruskal- Wallis test followed by Dunn's multiple comparison test. $P<0.05$

620 was considered statistically significant (symbols: ${ }^{* * * *} \mathrm{P}<0.0001 ; * * * \mathrm{P}<0.001 ;{ }^{* *} \mathrm{P}<0.01 ;{ }^{*} \mathrm{P}<$

621 0.05). Survival data were plotted using the Kaplan-Meier estimator and log-rank (Mantel-Cox) tests

622 were performed to assess differences between groups. Statistical analyses were performed using

623 GraphPad Prism ${ }^{\circledR}$ software. Statistical analyses for in ovo experiments, were performed using

624 GraphPrism version 7. Comparison of survival curves between different infection groups was carried

625 out with the Log-rank (Mantel-Cox) test. Comparisons of the means of L. pneumophila CFU counts

626 between groups were performed by the Mann-Whitney test. A p-value under 0.05 was considered

627 statistically significant.

629 Inoculation and quantification of $L$. pneumophila strains in in ovo experiments. Fertilized chicken

630 eggs purchased from a local producer (Saint-Maurice-sur-Dargoire, Rhône, France) were incubated at

$63135^{\circ} \mathrm{C}$ in an egg incubator (Maino, Italy) to maintain normal embryonic development. Eggs were

632 pathogen and antibiotic free. On day 0, 23 embryonated chicken eggs (ECE) were inoculated at 8

633 days of embryonation (DOE) with either L. pneumophila WT ( $n=9)$, L. pneumophila $\triangle \operatorname{dot} A(n=7)$ or

634 sterile PBS as control $(n=7)$. L. pneumophila concentration in WT and $\Delta$ dotA suspensions before ECE

635 injection was quantified at $9.2 \log _{10} \mathrm{CFU} / \mathrm{mL}$ and $9.1 \log _{10} \mathrm{CFU} / \mathrm{mL}$, respectively. L. pneumophila

636 concentration in the yolk sac of ECE directly after injection were estimated, considering both the

637 measured inoculum counts and the yolk sac volumes (median (interquartile range) [IQR] volume, 30

638 [28.7-31.2] mL), at 7.4 and $7.3 \log _{10} \mathrm{CFU} / \mathrm{mL}$ in the WT and $\Delta \operatorname{dot} A$ groups, respectively. Two-day

639 cultures of Lpp-WT and Lpp- $\triangle \operatorname{dot} A$ on BCYE at $36^{\circ} \mathrm{C}$ were suspended in PBS at a DO $=2.5 \mathrm{McF}$ arland

$640\left(9 \log _{10} \mathrm{CFU} / \mathrm{mL}\right)$ and $0.5 \mathrm{~mL}$ of suspensions or PBS as negative control were inoculated in the yolk sac

641 of ECE. After inoculation, ECE were candled every 24 hours to assess embryo viability until day- 6 post

642 infection. Embryos that died the day after inoculation ( $n=2$, corresponding to one WT-infected and

643 one $\Delta \operatorname{dot} A$-infected embryo) were discarded for L. pneumophila quantification as death was probably 
bioRxiv preprint doi: $\mathrm{https}$ ://doi.org/10.1101/2021.10.18.464513; this version posted October 19, 2021. The copyright holder for this preprint (which was not certified by peer review) is the author/funder, who has granted bioRxiv a license to display the preprint in perpetuity. It is made available under aCC-BY-NC-ND 4.0 International license.

644 due to bad inoculation. Dead embryos were stored at $4^{\circ} \mathrm{C}$ overnight prior to harvesting the yolk sacs.

645 Remaining live embryos at 6-days post injection were euthanized by refrigeration overnight and the

646 yolk sacs were collected. After measuring their volume, yolk sacs were crushed using gentleMACS ${ }^{\mathrm{TM}}$

647 Octo Dissociator (Miltenyi Biotec, Germany) and $100 \mu \mathrm{L}$ of serial dilutions at $10^{-2}, 10^{-4}$ and $10^{-6}$ were 648 automatically plated using easySpiral ${ }^{\circledR}$ automatic plater (Interscience, France) in triplicates on BCYE

649 agar. L. pneumophila were quantified after 5 days-incubation using Scan ${ }^{\circledR} 1200$ Automatic HD colony counter (Interscience, France).

651

\section{Author contributions}

$653 \mathrm{FV}, \mathrm{LB}, \mathrm{DS}, \mathrm{VL}, \mathrm{MI}$ and ECG performed the experiments, FV, SJ, LB, ECG and CB designed the experiments, FV, LB, ECG analyzed the experiments, VL performed IMARIS analysis of the raw confocal high resolution acquisition data, FV, ECG and CB wrote the article, ECG and CB supervised the work and acquired funds.

\section{Competing Interest}

The authors declare there are no competing interests.

660

\section{1}

662

663

664

665

666

\section{ACKNOWLEDGEMENTS}

We thank Pedro Escoll and Jean-Pierre Levraud for help and ideas in the initial set up of the project and Tobias Sahr for critical reading and helpful discussions and Yohann Rolin and Noël Aimar for their excellent care of the fish. Work in the CB laboratory is financed by the Institut Pasteur, the Fondation pour la Recherche Médicale (FRM) grant N EQU201903007847 and the grant nANR-10-LABX-62IBEID. Work in ECG group is financed by Institut Pasteur, CNRS, and ANR grant $N^{\circ} 17-C E 15-0026$. Valerio Laghi is funded by ANR grant TIFAsomes. We wish to thank the fish facility (Yohann Rolin and Noël Aimar) for their excellent care of the fish. The funders, other than the authors, did not play any role in the study or in the preparation of the article or decision to publish.

\section{REFERENCES}

1 Fliermans, C. B. Ecology of Legionella: From Data to Knowledge with a Little Wisdom. Microb Ecol 32, 203-228 (1996).

2 Cunha, B. A., Burillo, A. \& Bouza, E. Legionnaires' disease. Lancet 387, 376-385, doi:10.1016/S0140-6736(15)60078-2 (2016).

3 Rowbotham, T. J. Preliminary report on the pathogenicity of Legionella pneumophila for freshwater and soil amoebae. J Clin Pathol 33, 1179-1183 (1980).

4 Boamah, D. K., Zhou, G., Ensminger, A. W. \& O'Connor, T. J. From Many Hosts, One Accidental Pathogen: The Diverse Protozoan Hosts of Legionella. Frontiers in cellular and infection microbiology 7, 477, doi:10.3389/fcimb.2017.00477 (2017). 
bioRxiv preprint doi: https://doi.org/10.1101/2021.10.18.464513; this version posted October $19,2021$. The copyright holder for this preprint (which was not certified by peer review) is the author/funder, who has granted bioRxiv a license to display the preprint in perpetuity. It is made available under aCC-BY-NC-ND 4.0 International license.

6815 Mampel, J. et al. Planktonic replication is essential for biofilm formation by Legionella

682

683

684

685

686

687

688

689

690

691

692

693

694

695

696

697

698

699

700

701

702

703

704

705

706

707

708

709

710

711

712

713

714

715

716

717

718

719

720

721

722

723

724

725

726

727

728

729

730

731 pneumophila in a complex medium under static and dynamic flow conditions. Appl Environ Microbiol 72, 2885-2895, doi:10.1128/AEM.72.4.2885-2895.2006 (2006).

6 McDade, J. E. et al. Legionnaires' disease: isolation of a bacterium and demonstration of its role in other respiratory disease. N Engl J Med 297, 1197-1203 (1977).

7 Lanternier, F. et al. Legionnaire's Disease in Compromised Hosts. Infect Dis Clin North Am 31, 123135, doi:10.1016/j.idc.2016.10.014 (2017).

8 Naujoks, J., Lippmann, J., Suttorp, N. \& Opitz, B. Innate sensing and cell-autonomous resistance pathways in Legionella pneumophila infection. Int J Med Microbiol 308, 161-167, doi:10.1016/j.ijmm.2017.10.004 (2018).

9 Isberg, R. R., O'Connor, T. J. \& Heidtman, M. The Legionella pneumophila replication vacuole: making a cosy niche inside host cells. Nat Rev Microbiol 7, 13-24, doi:nrmicro1967 [pii]10.1038/nrmicro1967 (2009).

10 Mondino, S. et al. Legionnaires' Disease: State of the Art Knowledge of Pathogenesis Mechanisms of Legionella. Annu Rev Pathol 15, 439-466, doi:10.1146/annurev-pathmechdis-012419-032742 (2020).

11 Ensminger, A. W. Legionella pneumophila, armed to the hilt: justifying the largest arsenal of effectors in the bacterial world. Curr Opin Microbiol 29, 74-80, doi:10.1016/j.mib.2015.11.002 (2016).

12 Cazalet, C. et al. Evidence in the Legionella pneumophila genome for exploitation of host cell functions and high genome plasticity. Nat Genet 36, 1165-1173 (2004).

13 Mondino, S., Schmidt, S. \& Buchrieser, C. Molecular Mimicry: a Paradigm of Host-Microbe Coevolution Illustrated by Legionella. mBio 11, doi:10.1128/mBio.01201-20 (2020).

14 Brassinga, A. K. et al. Caenorhabditis is a metazoan host for Legionella. Cell Microbiol 12, 343-361, doi:CMI1398 [pii]10.1111/j.1462-5822.2009.01398.x (2009).

15 Harding, C. R. et al. Legionella pneumophila pathogenesis in the Galleria mellonella infection model. Infect Immun 80, 2780-2790, doi:10.1128/IAI.00510-12 (2012).

16 Brown, A. S., van Driel, I. R. \& Hartland, E. L. Mouse Models of Legionnaires' Disease. Curr Top Microbiol 376, 271-291, doi:10.1007/82_2013_349 (2014).

17 Breiman, R. F. \& Horwitz, M. A. Guinea pigs sublethally infected with aerosolized Legionella pneumophila develop humoral and cell-mediated immune responses and are protected against lethal aerosol challenge. A model for studying host defense against lung infections caused by intracellular pathogens. J Exp Med 165, 799-811 (1987).

18 Weeratna, R. et al. Human and guinea pig immune responses to Legionella pneumophila protein antigens OmpS and Hsp60. Infect Immun 62, 3454-3462 (1994).

19 Masud, S., Torraca, V. \& Meijer, A. H. Modeling Infectious Diseases in the Context of a Developing Immune System. Curr Top Dev Biol 124, 277-329, doi:10.1016/bs.ctdb.2016.10.006 (2017).

20 Torraca, V. \& Mostowy, S. Zebrafish Infection: From Pathogenesis to Cell Biology. Trends in Cell Biology 28, 143-156, doi:10.1016/j.tcb.2017.10.002 (2018).

21 Gomes, M. C. \& Mostowy, S. The Case for Modeling Human Infection in Zebrafish. Trends in Microbiology 28, 10-18, doi:10.1016/j.tim.2019.08.005 (2020).

22 Colucci-Guyon, E., Tinevez, J. Y., Renshaw, S. A. \& Herbomel, P. Strategies of professional phagocytes in vivo: unlike macrophages, neutrophils engulf only surface-associated microbes. $J$ Cell Sci 124, 3053-3059, doi:10.1242/jcs.082792 (2011).

23 Herbomel, P., Thisse, B. \& Thisse, C. Ontogeny and behaviour of early macrophages in the zebrafish embryo. Development 126, 3735-3745 (1999).

24 Liu, X. \& Shin, S. Viewing Legionella pneumophila Pathogenesis through an Immunological Lens. J Mol Biol 431, 4321-4344, doi:10.1016/j.jmb.2019.07.028 (2019).

25 Cohen, S. B. et al. Alveolar Macrophages Provide an Early Mycobacterium tuberculosis Niche and Initiate Dissemination. Cell Host Microbe 24, 439-446 e434, doi:10.1016/j.chom.2018.08.001 (2018). 
bioRxiv preprint doi: https://doi.org/10.1101/2021.10.18.464513; this version posted October $19,2021$. The copyright holder for this preprint (which was not certified by peer review) is the author/funder, who has granted bioRxiv a license to display the preprint in perpetuity. It is made available under aCC-BY-NC-ND 4.0 International license.

26 Mengue, L. et al. Legionella pneumophila decreases velocity of Acanthamoeba castellanii. Exp Parasitol 183, 124-127, doi:10.1016/j.exppara.2017.07.013 (2017).

27 Simon, S., Wagner, M. A., Rothmeier, E., Muller-Taubenberger, A. \& Hilbi, H. Icm/Dot-dependent inhibition of phagocyte migration by Legionella is antagonized by a translocated Ran GTPase activator. Cell Microbiol 16, 977-992, doi:10.1111/cmi.12258 (2014).

28 Mostowy, S. et al. The zebrafish as a new model for the in vivo study of Shigella flexneri interaction with phagocytes and bacterial autophagy. PLoS Pathog 9, e1003588, doi:10.1371/journal.ppat.1003588 (2013).

$29 \mathrm{Su}, \mathrm{F}$. et al. Differential regulation of primitive myelopoiesis in the zebrafish by Spi-1/Pu.1 and C/ebp1. Zebrafish 4, 187-199, doi:10.1089/zeb.2007.0505 (2007).

30 Ellett, F., Pase, L., Hayman, J. W., Andrianopoulos, A. \& Lieschke, G. J. mpeg1 promoter transgenes direct macrophage-lineage expression in zebrafish. Blood 117, e49-56, doi:10.1182/blood-201010-314120 (2011).

31 Palha, N. et al. Real-time whole-body visualization of Chikungunya Virus infection and host interferon response in zebrafish. PLoS Pathog 9, e1003619, doi:10.1371/journal.ppat.1003619 (2013).

32 Phan, Q. T. et al. Neutrophils use superoxide to control bacterial infection at a distance. Plos Pathogens 14, doi:ARTN e100715710.1371/journal.ppat.1007157 (2018).

33 Copenhaver, A. M., Casson, C. N., Nguyen, H. T., Duda, M. M. \& Shin, S. IL-1R signaling enables bystander cells to overcome bacterial blockade of host protein synthesis. Proc Natl Acad Sci U S A 112, 7557-7562, doi:10.1073/pnas.1501289112 (2015).

34 Friedman, H., Yamamoto, Y. \& Klein, T. W. Legionella pneumophila pathogenesis and immunity. Semin Pediatr Infect Dis 13, 273-279, doi:10.1053/spid.2002.127206 (2002).

35 Asrat, S., de Jesus, D. A., Hempstead, A. D., Ramabhadran, V. \& Isberg, R. R. Bacterial pathogen manipulation of host membrane trafficking. Annu Rev Cell Dev Biol 30, 79-109, doi:10.1146/annurev-cellbio-100913-013439 (2014).

36 Archer, K. A., Alexopoulou, L., Flavell, R. A. \& Roy, C. R. Multiple MyD88-dependent responses contribute to pulmonary clearance of Legionella pneumophila. Cell Microbiol 11, 21-36, doi:CMI1234 [pii]10.1111/j.1462-5822.2008.01234.x (2009).

37 Archer, K. A. \& Roy, C. R. MyD88-dependent responses involving toll-like receptor 2 are important for protection and clearance of Legionella pneumophila in a mouse model of Legionnaires' disease. Infect Immun 74, 3325-3333, doi:74/6/3325 [pii]10.1128/IAI.02049-05 (2006).

38 Hawn, T. R., Smith, K. D., Aderem, A. \& Skerrett, S. J. Myeloid differentiation primary response gene (88)- and toll-like receptor 2-deficient mice are susceptible to infection with aerosolized Legionella pneumophila. J Infect Dis 193, 1693-1702, doi:10.1086/504525 (2006).

39 Sporri, R., Joller, N., Albers, U., Hilbi, H. \& Oxenius, A. MyD88-dependent IFN-gamma production by NK cells is key for control of Legionella pneumophila infection. J Immunol 176, 6162-6171, doi:176/10/6162 [pii] (2006).

40 Mallama, C. A., McCoy-Simandle, K. \& Cianciotto, N. P. The Type II Secretion System of Legionella pneumophila Dampens the MyD88 and Toll-Like Receptor 2 Signaling Pathway in Infected Human Macrophages. Infect Immun 85, doi:10.1128/IAI.00897-16 (2017).

41 Rolando, M. et al. Legionella pneumophila S1P-lyase targets host sphingolipid metabolism and restrains autophagy. Proc Natl Acad Sci U S A 113, 1901-1906, doi:10.1073/pnas.1522067113 (2016).

42 Fallon, R. J. \& Abraham, W. H. Polyvalent heat-killed antigen for the diagnosis of infection with Legionella pneumophila. J Clin Pathol 35, 434-438, doi:10.1136/jcp.35.4.434 (1982).

43 Levraud, J. P. et al. Real-time observation of Listeria monocytogenes-phagocyte interactions in living zebrafish larvae. Infect Immun 77, 3651-3660, doi:10.1128/IAI.00408-09 (2009).

44 Hosseini, R. et al. Efferocytosis and extrusion of leukocytes determine the progression of early mycobacterial pathogenesis. J Cell Sci 129, 3385-3395, doi:10.1242/jcs.135194 (2016).

45 Tesh, M. J. \& Miller, R. D. Amino acid requirements for Legionella pneumophila growth. J Clin Microbiol 13, 865-869 (1981). 
bioRxiv preprint doi: https://doi.org/10.1101/2021.10.18.464513; this version posted October $19,2021$. The copyright holder for this preprint (which was not certified by peer review) is the author/funder, who has granted bioRxiv a license to display the preprint in perpetuity. It is made available under aCC-BY-NC-ND 4.0 International license.

803

804

805

806

807

808

809

810

811

812

813

814

815

816

817

818

819

820

821

822

823

824

825

826

827

828

829

830

831

832

833

834

835

46 Fonseca, M. V. \& Swanson, M. S. Nutrient salvaging and metabolism by the intracellular pathogen Legionella pneumophila. Frontiers in cellular and infection microbiology $\mathbf{4}, \mathbf{1 2}$, doi:10.3389/fcimb.2014.00012 (2014).

47 Hauslein, I., Manske, C., Goebel, W., Eisenreich, W. \& Hilbi, H. Pathway analysis using (13) Cglycerol and other carbon tracers reveals a bipartite metabolism of Legionella pneumophila. Mol Microbiol 100, 229-246, doi:10.1111/mmi.13313 (2016).

48 Hauslein, I. et al. Legionella pneumophila CsrA regulates a metabolic switch from amino acid to glycerolipid metabolism. Open Biol 7, doi:10.1098/rsob.170149 (2017).

49 Fraher, D. et al. Zebrafish Embryonic Lipidomic Analysis Reveals that the Yolk Cell Is Metabolically Active in Processing Lipid. Cell Rep 14, 1317-1329, doi:10.1016/j.celrep.2016.01.016 (2016).

50 Brieland, J. et al. Replicative Legionella pneumophila lung infection in intratracheally inoculated A/J mice. A murine model of human Legionnaires' disease. Am J Pathol 145, 1537-1546 (1994).

51 Glavin, F. L., Winn, W. C., Jr. \& Craighead, J. E. Ultrastructure of lung in Legionnaires' disease. Observations of three biopsies done during the Vermont epidemic. Ann Intern Med 90, 555-559, doi:10.7326/0003-4819-90-4-555 (1979).

52 Horwitz, M. A. Formation of a novel phagosome by the Legionnaires' disease bacterium (Legionella pneumophila) in human monocytes. J Exp Med 158, 1319-1331 (1983).

53 Horwitz, M. A. \& Silverstein, S. C. Legionnaires' disease bacterium (Legionella pneumophila) multiples intracellularly in human monocytes. J Clin Invest 66, 441-450 (1980).

54 Jager, J. et al. Human lung tissue explants reveal novel interactions during Legionella pneumophila infections. Infect Immun 82, 275-285, doi:10.1128/IAl.00703-13 (2014).

55 Copenhaver, A. M. et al. Alveolar macrophages and neutrophils are the primary reservoirs for Legionella pneumophila and mediate cytosolic surveillance of type IV secretion. Infect Immun 82, 4325-4336, doi:10.1128/IAI.01891-14 (2014).

56 Bennett, C. M. et al. Myelopoiesis in the zebrafish, Danio rerio. Blood 98, 643-651, doi:10.1182/blood.v98.3.643 (2001).

57 Le Guyader, D. et al. Origins and unconventional behavior of neutrophils in developing zebrafish. Blood 111, 132-141, doi:10.1182/blood-2007-06-095398 (2008).

58 Willett, C. E., Cortes, A., Zuasti, A. \& Zapata, A. G. Early hematopoiesis and developing lymphoid organs in the zebrafish. Dev Dyn 214, 323-336, doi:10.1002/(SICI)10970177(199904)214:4<323::AID-AJA5>3.0.CO;2-3 (1999).

59 Mesureur, J. et al. Macrophages, but not neutrophils, are critical for proliferation of Burkholderia cenocepacia and ensuing host-damaging inflammation. PLoS Pathog 13, e1006437, doi:10.1371/journal.ppat.1006437 (2017).

60 Prajsnar, T. K., Cunliffe, V. T., Foster, S. J. \& Renshaw, S. A. A novel vertebrate model of Staphylococcus aureus infection reveals phagocyte-dependent resistance of zebrafish to non-host specialized pathogens. Cell Microbiol 10, 2312-2325, doi:10.1111/j.1462-5822.2008.01213.x (2008).

61 Jault, C., Pichon, L. \& Chluba, J. Toll-like receptor gene family and TIR-domain adapters in Danio rerio. Mol Immunol 40, 759-771, doi:10.1016/j.molimm.2003.10.001 (2004).

62 Meijer, A. H. et al. Expression analysis of the Toll-like receptor and TIR domain adaptor families of zebrafish. Mol Immunol 40, 773-783, doi:10.1016/j.molimm.2003.10.003 (2004).

63 Akira, S. \& Takeda, K. Toll-like receptor signalling. Nat Rev Immunol 4, 499-511, doi:10.1038/nri1391 (2004).

64 Wik, J. A. et al. Inflammatory activation of endothelial cells increases glycolysis and oxygen consumption despite inhibiting cell proliferation. FEBS Open Bio 11, 1719-1730, doi:10.1002/2211-5463.13174 (2021).

65 Hall, C., Flores, M. V., Storm, T., Crosier, K. \& Crosier, P. The zebrafish lysozyme C promoter drives myeloid-specific expression in transgenic fish. Bmc Dev Biol 7, doi:Artn 4210.1186/1471-213x-742 (2007).

66 Renshaw, S. A. et al. A transgenic zebrafish model of neutrophilic inflammation. Blood 108, 39763978, doi:10.1182/blood-2006-05-024075 (2006). 
bioRxiv preprint doi: https://doi org/10.1101/2021 10.18.464513. this version posted October 19, 2021. The copyright holder for this preprint (which was not certified by peer review) is the author/funder, who has granted bioRxiv a license to display the preprint in perpetuity. It is made available under aCC-BY-NC-ND 4.0 International license.

83667 van Leeuwen, L. M. et al. A transgenic zebrafish model for the in vivo study of the blood and choroid plexus brain barriers using claudin 5. Biol Open 7, doi:10.1242/bio.030494 (2018).

68 van der Vaart, M., van Soest, J. J., Spaink, H. P. \& Meijer, A. H. Functional analysis of a zebrafish myd88 mutant identifies key transcriptional components of the innate immune system. Dis Model Mech 6, 841-854, doi:10.1242/dmm.010843 (2013).

69 Tiaden, A. et al. The Legionella pneumophila response regulator LqsR promotes host cell interactions as an element of the virulence regulatory network controlled by RpoS and LetA. Cell Microbiol 9, 2903-2920, doi:CMI1005 [pii]10.1111/j.1462-5822.2007.01005.x (2007).

70 Levraud, J. P., Colucci-Guyon, E., Redd, M. J., Lutfalla, G. \& Herbomel, P. In vivo analysis of zebrafish innate immunity. Methods Mol Biol 415, 337-363, doi:10.1007/978-1-59745-570-1_20 (2008).

71 Brannon, M. K. et al. Pseudomonas aeruginosa Type III secretion system interacts with phagocytes to modulate systemic infection of zebrafish embryos. Cell Microbiol 11, 755-768, doi:10.1111/j.1462-5822.2009.01288.x (2009).

72 Colucci-Guyon, E. et al. Spatiotemporal analysis of mycolactone distribution in vivo reveals partial diffusion in the central nervous system. PLoS Negl Trop Dis 14, e0008878, doi:10.1371/journal.pntd.0008878 (2020).

853 
bioRxiv preprint doi: https://doi.org/10.1101/2021.10.18.464513; this version posted October 19, 2021. The copyright holder for this preprint (which was not certified by peer review) is the author/funder, who has granted bioRxiv a license to display the preprint in perpetuity. It is made available under aCC-BY-NC-ND 4.0 International license.

FIGURES LEGENDS

Figure 1. Zebrafish larvae are susceptible to intravenous $L$. pneumophila infection in a dose

858 dependend manner. A) Scheme of the experimental set up of bacterial infection using zebrafish. A

$85972 \mathrm{hpf}$ zebrafish larva is shown. Bacteria are injected in the bloodstream (iv) via the caudal vein

860 (green arrow). B) Survival curves (established from three independent experiments) of zebrafish

861 larvae injected with WT-GFP Low Dose (WT LD) (blue curve, $n=60$ ) or High Dose (HD) (red curve, $\mathrm{n}=60$ ), or with $\triangle \operatorname{dot} A$-GFP Low Dose ( $\Delta \operatorname{dot} A \mathrm{LD}$ ) (green curve, $\mathrm{n}=12$ ) or High Dose ( $\Delta \operatorname{dot} A \mathrm{HD}$ ) (green curve, $n=36)$, and incubated at $28^{\circ} \mathrm{C}$. Non-injected fish (CTRL, black curve; $\left.n=24\right)$. Three independent experiments. C) Bacterial burden quantification by enumerating live bacteria in homogenates from individual larvae infected with WT-GFP Low Dose (blue symbols) or High Dose (red symbols), or with $\Delta$ dotA-GFP High Dose (green symbols) measured by FACS immediately after L. pneumophila injection and $24 \mathrm{~h}, 48 \mathrm{~h}$ and $72 \mathrm{~h}$ post $L$. pneumophila injection. $\mathrm{n}=10$ larvae for each condition. D) Representative images of $L$. pneumophila dissemination, determined by live imaging using a fluorescence stereomicroscope, of zebrafish AB larvae infected with a LD or a HD of WT-GFP, or a HD of $\Delta$ dotA-GFP. The same infected larvae were live imaged $4 \mathrm{~h}, 24 \mathrm{~h}, 48 \mathrm{~h}$, and $72 \mathrm{~h}$ post injection of the different $L$. pneumophila strains. GFP fluorescence of the injected bacteria is shown.

Figure 2. Bloodstream L. pneumophila establish a proliferative niche in the yolk causing a persistent local infection. Characterization of the L. pneumophila foci growing in the yolk region of zebrafish larvae. Maximum intensity projection of confocal acquisition using high resolution fluorescent microscope. A) $72 \mathrm{hpf}$ mfap4: mCherry larva (red macrophages) injected in the bloodstream with HD of WT-GFP and followed over time with confocal fluorescent microscopy. B) Imaris 3D reconstruction and volume rendering of the L. pneumophila growth in the yolk of the same infected larva at $72 \mathrm{hpi}$, shown laterally. Inset shows the maximum intensity projection of the L. pneumophila foci in the same larva mounted ventrally. C) Scheme of $72 \mathrm{hpf}$ larva indicating with green dots the yolk sustaining L. pneumophila growing. D) Imaris 3D reconstruction and volume rendering of the L. pneumophila 882 growth (GFP labelling) in the yolk of the same infected larva at $72 \mathrm{hpi}$, showed ventrally. E) Imaris 3D 883 reconstruction and volume rendering of the L. pneumophila growth in the yolk of lyz:DsRed (red 884 neutrophils) infected larva at $72 \mathrm{hpi}$, showed laterally. F) Imaris 3D reconstruction and volume rendering of the L. pneumophila growth (GFP labelling) in the yolk of wild type AB infected larva at $72 \mathrm{hpi}$, showed laterally. Overlay of GFP and mCherry, or DsRed fluorescence is shown (2B, E, G), and S1-S4. 
bioRxiv preprint doi: https://doi.org/10.1101/2021.10.18.464513; this version posted October 19, 2021. The copyright holder for this preprint (which was not certified by peer review) is the author/funder, who has granted bioRxiv a license to display the preprint in perpetuity. It is made available under aCC-BY-NC-ND 4.0 International license.

889 Figure 3. L. pneumophila high dose infection results in (systemic) macrophage and neutrophil

890 death. A) Representative images of L. pneumophila dissemination, determined by live imaging using 891 a fluorescence stereomicroscope of zebrafish $\operatorname{Tg}(m f a p 4:: m C h e r r y F)$ larvae infected with a Low Dose 892 or a HD of WT-GFP, or a HD of $\Delta$ dotA-GFP. The same infected larvae were live imaged $4 \mathrm{~h}, 24 \mathrm{~h}, 48 \mathrm{~h}$, 893 and $72 \mathrm{~h}$ post $L$. pneumophila injection. Overlay of GFP and mCherry fluorescence is shown.

894 B) Macrophage counts in uninfected larvae (black symbols) or upon Low Dose (blue symbols) or High 895 Dose of WT-GFP (red symbols), or High Dose (green symbols) of $\Delta \operatorname{dot} A$-GFP injections. Macrophages 896 were counted manually from images taken on live infected larvae, using ImageJ software, and results 897 were plotted using GraphPad Prism ${ }^{\circledR}$ software. Mean \pm SEM are also shown (horizontal bars). Data 898 plotted are from two pooled independent experiments ( $n=12$ larvae scored for each condition).

899 C) Representative images of L. pneumophila dissemination, determined by live imaging using a 900 fluorescence stereomicroscope, of zebrafish $\operatorname{Tg}(\operatorname{Lys} C: \text { :DsRed })^{\text {nz50 }}$ larvae infected with a Low Dose or a 901 High Dose of WT-GFP or a High Dose of $\triangle \operatorname{dotA}$-GFP. The same infected larvae were live imaged $4 \mathrm{~h}$, 902 24h, 48h, and 72h post L. pneumophila injection. Overlay of GFP and DsRed fluorescence is shown.

903 D) Neutrophil counts in uninfected (CTRL, black symbols) or upon Low Dose or High Dose of WT-GFP 904 (blue or red symbols), or High Dose of $\Delta$ dotA-GFP (green symbols) injections. Data plotted in the 905 same way as for macrophage counts, are from two pooled independent experiments ( $n=10$ larvae 906 scored for each condition).

908 Figure 4. Live imaging of macrophage and neutrophil interaction with L. pneumophila

909 Frames extracted from maximum intensity projection of in vivo time-lapse confocal fluorescent

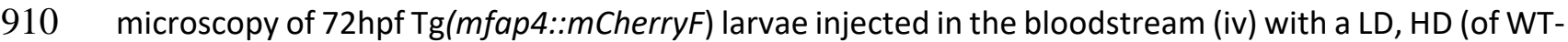
911 GFP or a HD of $\triangle$ dotA-GFP (upper panel) or $\operatorname{Tg}(L y s C:: D s R e d)^{n 250}$ in the bloodstream (iv) with a LD, HD of 912 WT-GFP or a HD of $\triangle \operatorname{dotA-GFP}$ (lower panel) to follow macrophage and neutrophil interaction with $L$. 913 pneumophila respectively. Images were taken from time lapse at different time points (Ohpi, $2 \mathrm{hpi}$, 914 4hpi, 8hpi and 16hpi). Overlay of green (L. pneumophila) and red (leucocytes) fluorescence of the 915 caudal area of the larvae (region boxed in the scheme on the right of the panel) is shown. Scale bar: $91650 \mu \mathrm{m}$. See also related Movies S5, S6.

918 Figure 5. Macrophages are crucial to restrict Legionella pneumophila dissemination

919 A) Survival curves of CTRL morphant zebrafish larvae injected with a Low Dose (LD) (blue dashed 920 curve, $n=34$ larvae) or a High Dose (HD) (red dashed curve, $n=34$ ) of WT-GFP, or with a HD (green 921 dashed curve, $\mathrm{n}=24$ ) of $\Delta \operatorname{dot} A$-GFP, and spi1b morphant zebrafish larvae injected with a LD (blue 922 curve, $n=48$ ) or a HD (red curve, $n=48$ ) of WT-GFP, or with a High Dose (HD) (green curve, $n=48$ ) of $923 \Delta$ dotA -GFP. Non-injected CTRL morphant fish (black dashed curve, $\mathrm{n}=48$ ), and spi1b morphant fish 
bioRxiv preprint doi: https://doi.org/10.1101/2021.10.18.464513; this version posted October $19,2021$. The copyright holder for this preprint (which was not certified by peer review) is the author/funder, who has granted bioRxiv a license to display the preprint in perpetuity. It is made available under aCC-BY-NC-ND 4.0 International license.

924 (black curves, $n=48$ ) were used as control. Infected and control larvae were incubated at $28^{\circ} \mathrm{C}$. Data

925 plotted are from two pooled independent experiments. B) and E) Bacterial burden quantification by

926 enumerating live bacteria in homogenates from individual larvae infected with LD of WT-GFP (blue

927 symbols) or HD (red symbols), or with LD of $\triangle$ dotA-GFP (magneta symbols) or HD (green symbols),

928 measured by plating onto BCYE agar plates supplemented with Chloramphenicol and the Legionella

929 Selective Supplement GVPN immediately after $L$. pneumophila injection and $24 \mathrm{~h}, 48 \mathrm{~h}$ and $48 \mathrm{~h}$ post $L$.

930 pneumophila injection. $\mathrm{n}=10$ larvae for each condition. D) Survival curves of CTRL morphant zebrafish

931 larvae injected with a LD (blue dashed curve, $n=36$ ) or a HD (red dashed curve, $n=36$ ) of WT-GFP, or

932 with a HD (green dashed curve, $\mathrm{n}=24$ ) of $\Delta$ dotA -GFP, and csf3r morphant zebrafish larvae injected

933 with a LD (blue curve, $n=24$ ) or a HD (red curve, $n=36$ ) of WT-GFP, or with a HD (green curve, $n=36$ ) of

$934 \Delta \operatorname{dot} A$-GFP. Non-injected CTRL morphant fish (black dashed curve, $\mathrm{n}=48$ ), and csf3r morphant fish

935 (black curve, $n=36$ ) were used as control. Data plotted are from two pooled independent

936 experiments. C) and F) Representative images of L. pneumophila dissemination, determined by live

937 imaging using a fluorescence stereomicroscope, of $\operatorname{Tg}$ (mfap4::mCherryF) spe1b morphant larvae (C)

938 and of $\operatorname{Tg}(\text { LysC::DsRed })^{\text {nz50 }}$ (F) csf3r morphant larvae non infected, or infected with a LD or a HD of

939 WT-GFP, or a HD of $\triangle$ dotA-GFP. The same infected larvae were live imaged $4 \mathrm{~h}, 24 \mathrm{~h}, 48 \mathrm{~h}$, and $72 \mathrm{~h}$

940 post L. pneumophila injection. Overlay of GFP and mCherry fluorescence is shown.

942 Figure 6. Zebrafish larva Immunity to L. pneumophila is independent from signalling through

943 MyD88 or compensated by other signalling pathways. A) Survival curves of CTRL zebrafish larvae

944 injected with WT-GFP Low Dose (LD) (blue dashed curve) or High Dose (HD) (red dashed curve), or

945 with $\triangle \operatorname{dotA}$-GFP HD (green dashed curve), and myd88 ${ }^{\text {hu} 3568}$ mutant zebrafish larvae injected with WT-

946 GFP LD (blue curve) or HD (red curve), or with $\triangle$ dotA -GFP HD (green curve). Non-injected CTRL

947 larvae (black dashed curves), and myd88 $8^{\text {hu3568 }}$ mutant larvae (black curves) were used as control.

948 Infected and control larvae ( $\mathrm{n}=72$ fish for $m y d 88^{\text {hu3568 }}$ mutant conditions and $\mathrm{n}=57$ fish for CTRL

949 conditions) were incubated at $28^{\circ} \mathrm{C}$. Data plotted are from 3 pooled independent experiments. B)

950 Bacterial Burden of $m y d 88^{\text {hu}} 3568$ mutant zebrafish larvae are the same as what is observed for control

951 larvae. Bacterial burden quantification by enumerating live bacteria in homogenates from individual

952 larvae infected with WT-GFP LD (blue symbols) or HD (red symbols), or with $\triangle \operatorname{dotA}$-GFP HD (green

953 symbols) were measured by plating onto BCYE agar plates supplemented with Chloramphenicol and

954 the L. pneumophila Selective Supplement GVPN immediately after Legionella injection and $24 \mathrm{~h}, 48 \mathrm{~h}$

955 and $48 \mathrm{~h}$ post Legionella injection. $\mathrm{n}=15$ larvae for each condition. C-D) Cytokine (il1b, tnfa) induction

956 was measured from individual myd88 $8^{\text {hu}} 3568$ mutant larvae injected with a HD (red curves) of WT-GFP

957 and non-injected fish as control (CTRL, black curves). The same colours are used in individual CTRL

958 zebrafish with dashed curves. Data plotted are from one experiment ( $n=5$ larvae for each condition); 
959 individual values are shown, and curves correspond to the medians. There is no statistically

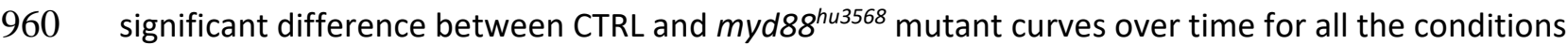

961 analysed.

962

963 Figure 7. L. pneumophila replication in the yolk of zebrafish larvae is T4SS dependent. A) Survival

964 curves of zebrafish larvae injected with WT-GFP Low Dose (LD) (blue curve) or High Dose (HD) (red

965 curve), or with $\triangle \operatorname{dotA-GFP}$ LD (magenta curve) or HD (green curve). Non-injected larvae (black

966 curves) were used as control. $n=48$ larvae per conditions. All larvae were incubated at $28^{\circ} \mathrm{C}$. Data

967 plotted are from two pooled independent experiments. B) Bacterial burden quantification of

968 zebrafish larvae injected with L. pneumophila in the yolk cell, by enumerating live bacteria in

969 homogenates from individual larvae infected with WT-GFP LD (blue symbols) or HD (red symbols), or

970 with $\triangle$ dotA-GFP Low Dose (LD) (magenta symbols) or HD (green symbols). They were measured by

971 plating onto BCYE agar plates supplemented with Chloramphenicol and the Legionella Selective

972 Supplement GVPN immediately after L. pneumophila injection and $24 \mathrm{~h}, 48 \mathrm{~h}$ and $48 \mathrm{~h}$ post Legionella

973 injection. $\mathrm{n}=10$ larvae for each condition. C-D) Representative images of $L$. pneumophila

974 dissemination, determined by live imaging using a fluorescence stereomicroscope, of

$975 \operatorname{Tg}(\text { LysC::DsRed })^{\text {nz50 }}$ not infected zebrafish larvae, or infected with a Low Dose of WT-GFP or $\Delta$ dotA -

976 GFP (C), or infected with a High Dose of WT-GFP or $\triangle$ dotA -GFP (D). The same infected larvae were

977 live imaged $4 \mathrm{~h}, 24 \mathrm{~h}, 48 \mathrm{~h}$, and $72 \mathrm{~h}$ post L. pneumophila injection. Overlay of GFP and mCherry

978 fluorescence is shown. 


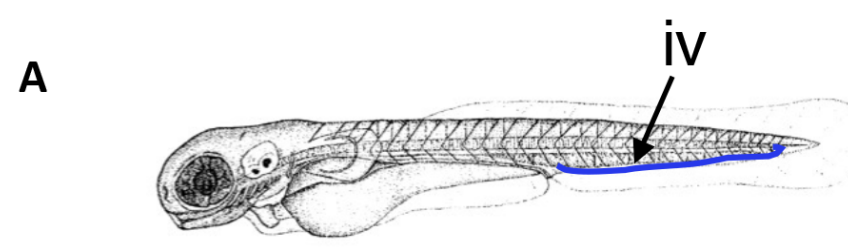

B

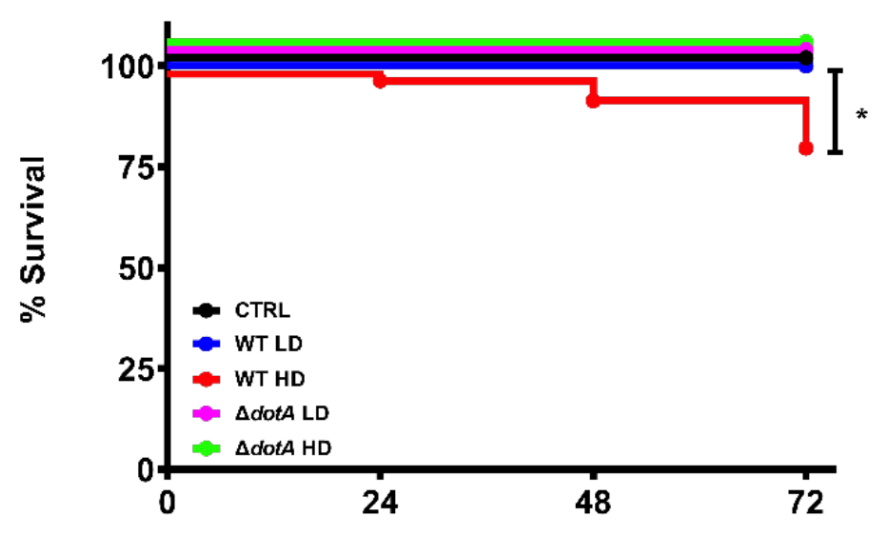

Hours post-injection

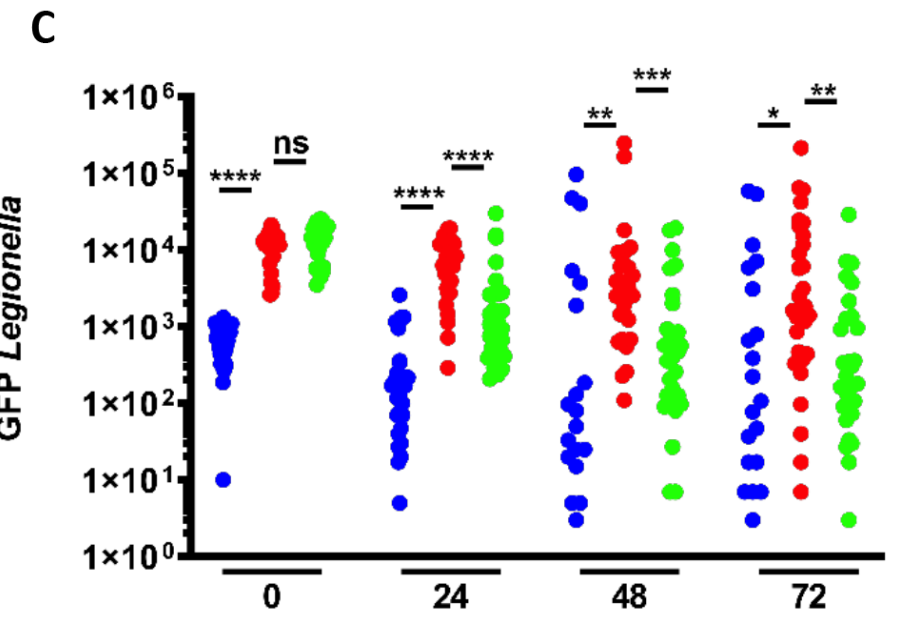

Hours post-injection

D

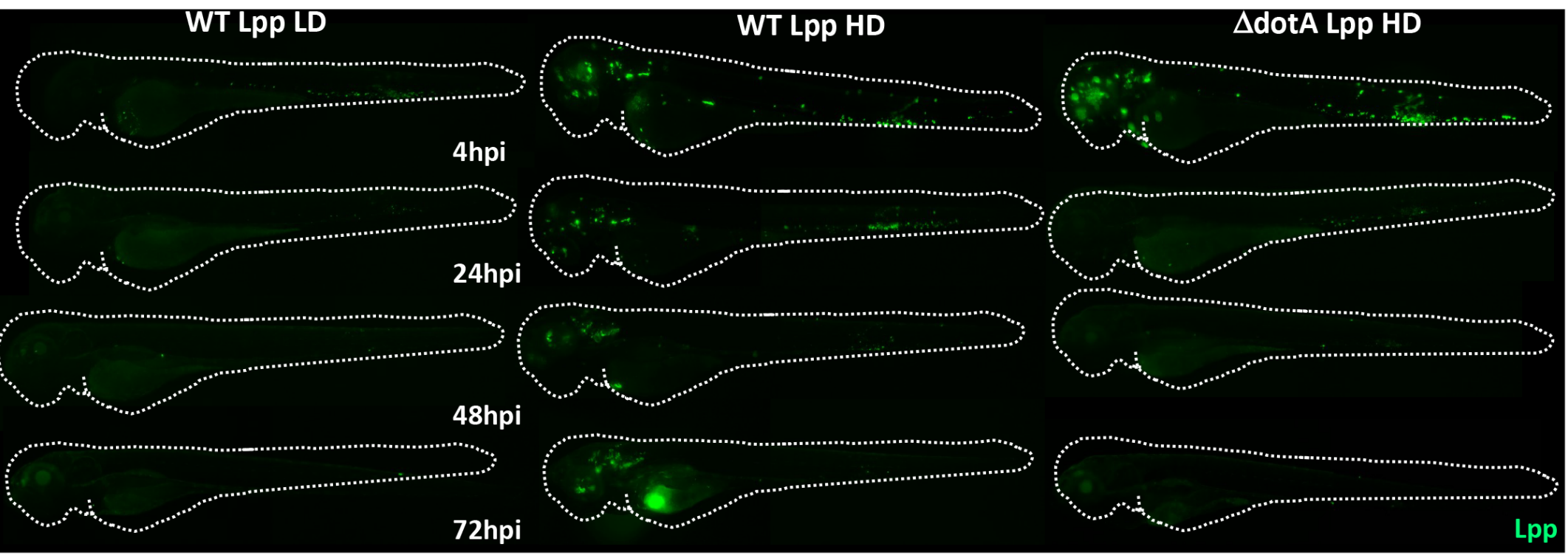



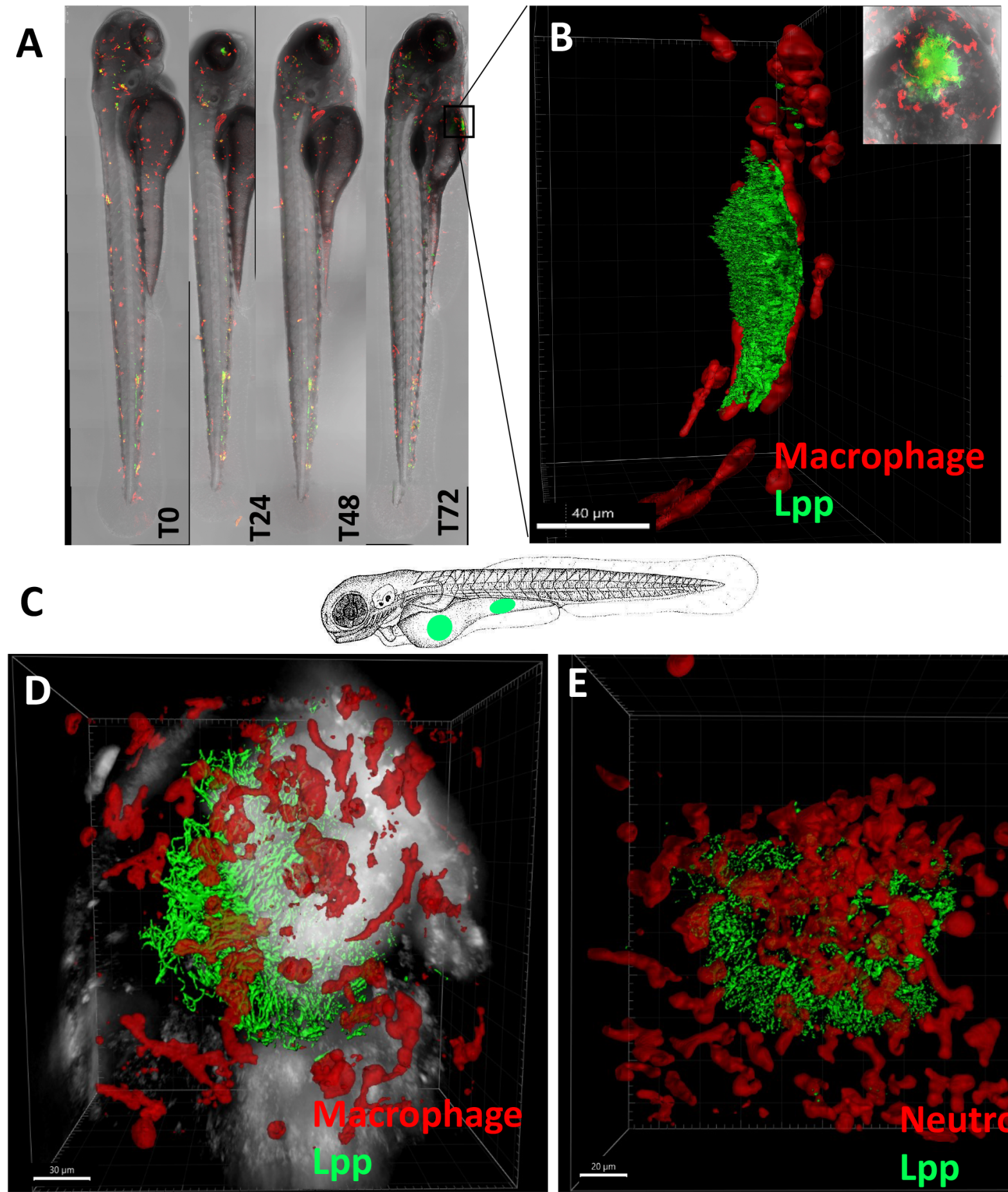

E

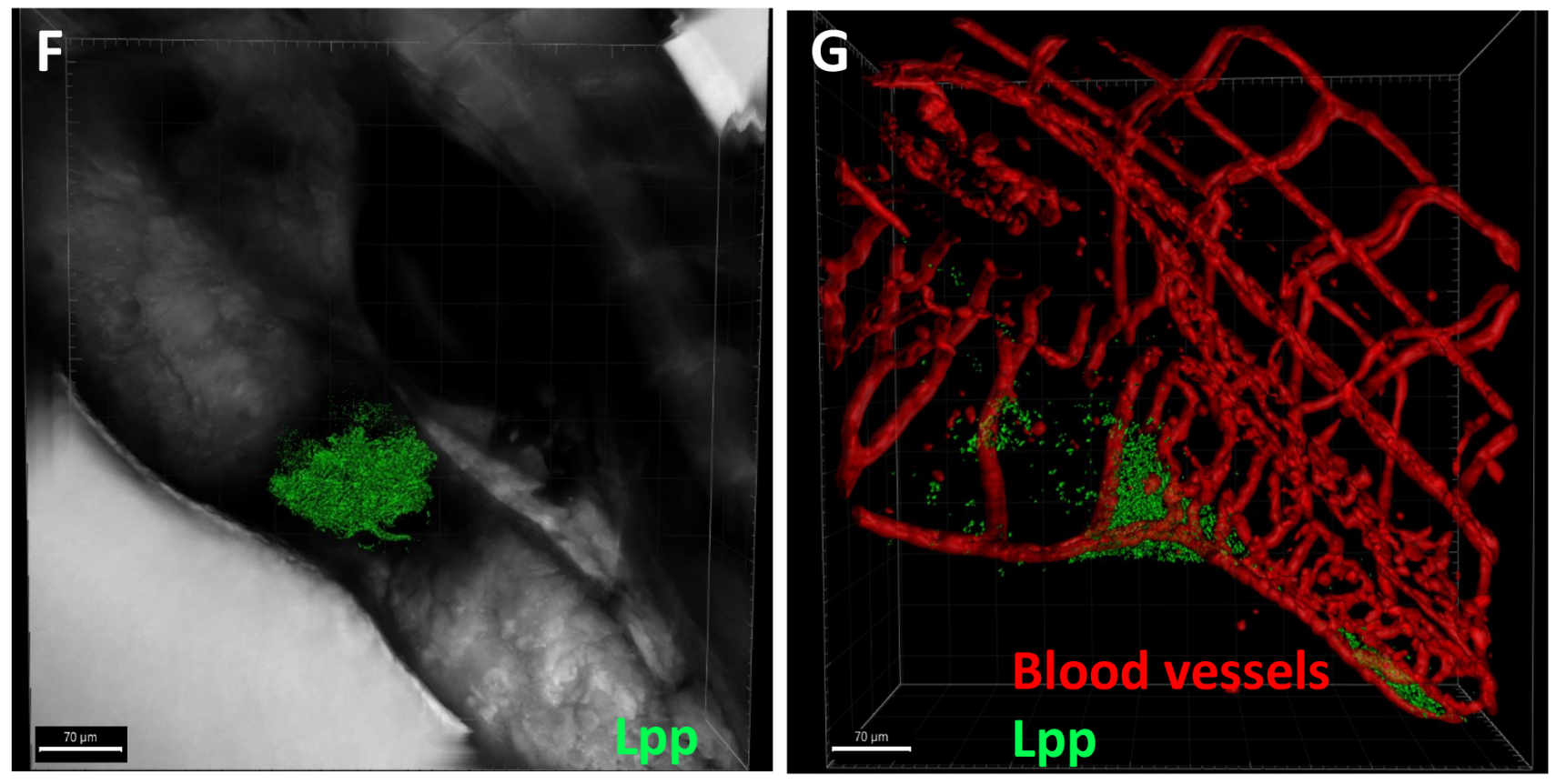


A

4hpi

24hpi

48hpi

72hpi

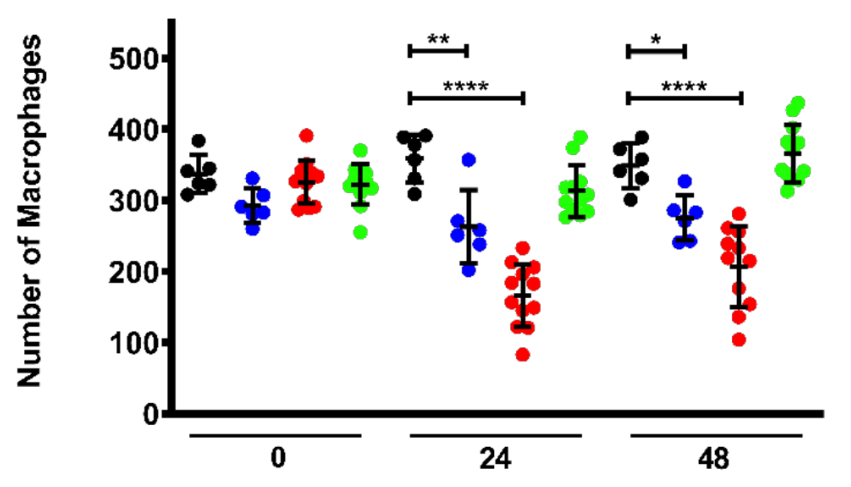

- Non-infected

- WT LD

- WT HD

$\triangle$ dota HD

Hours post-injection

C WT LD

WT HD

$\Delta \operatorname{dot} A$ HD

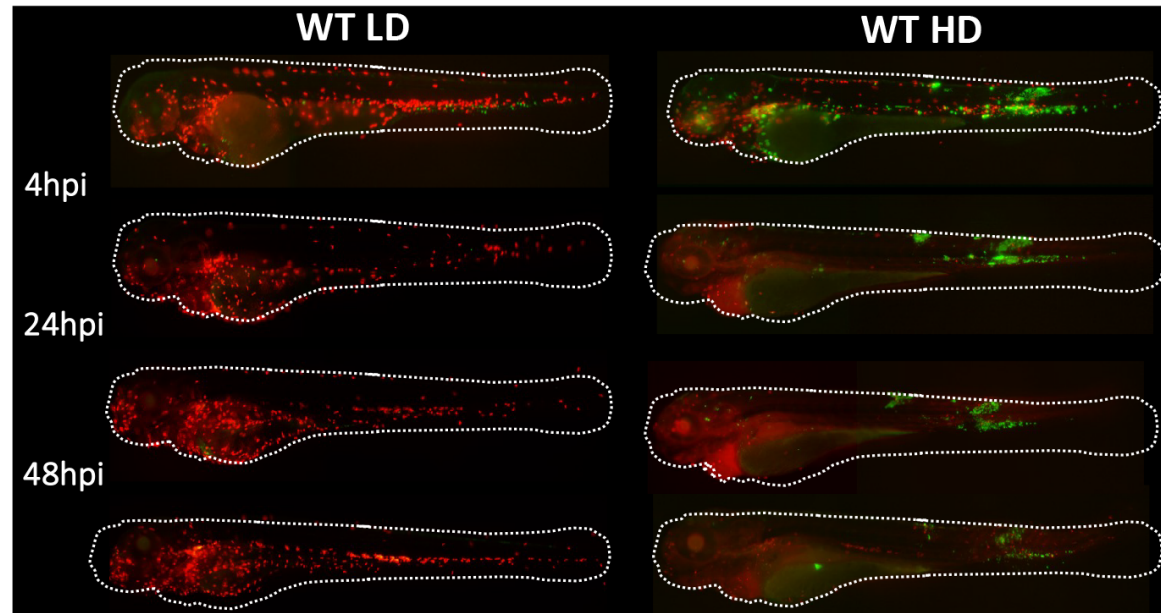

72hpi

D

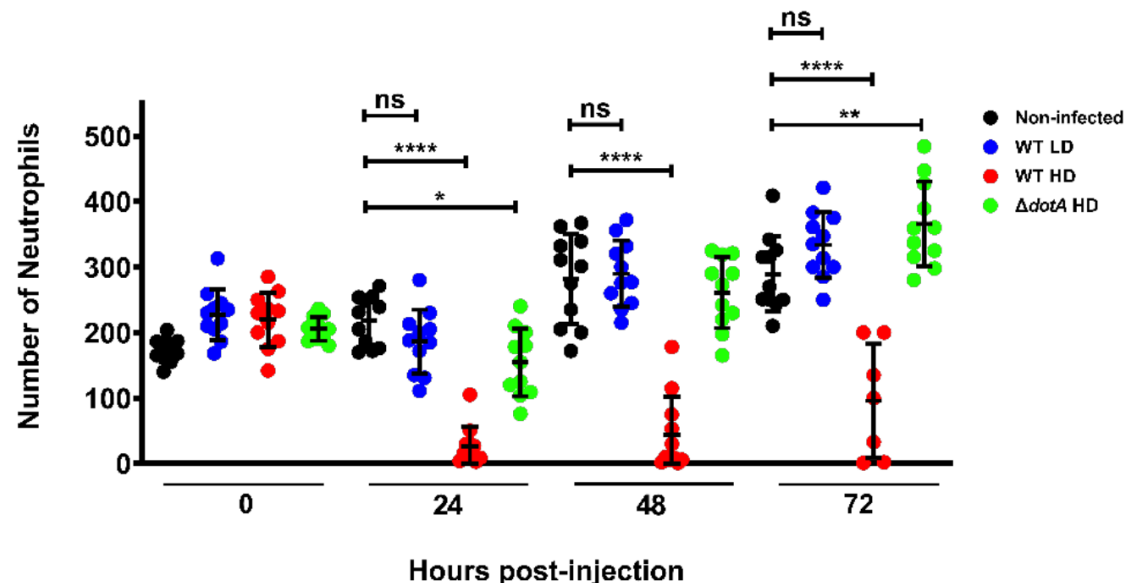


Macrophage-Lpp interactions over time

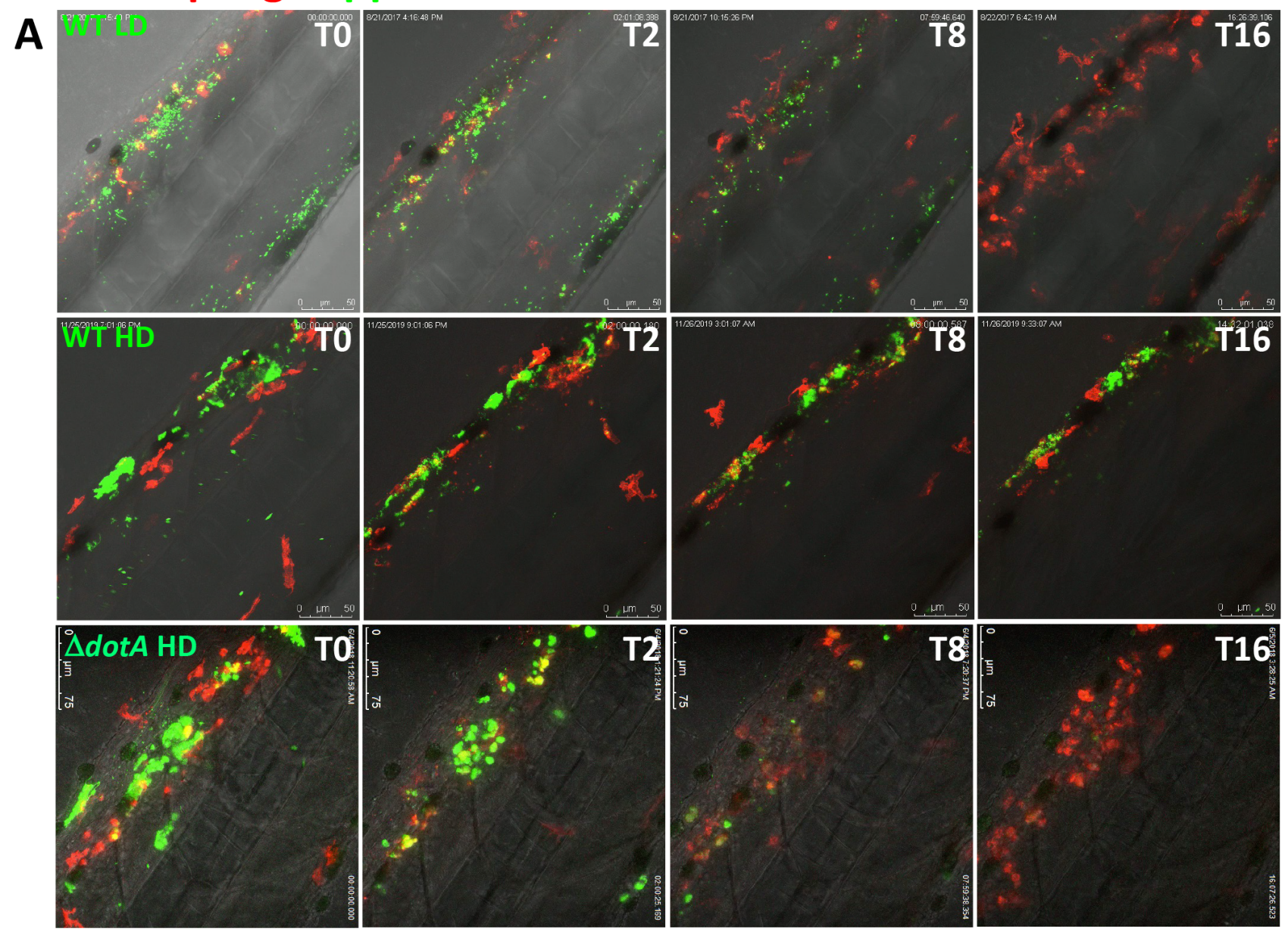

\section{Neutrophil-Lpp interactions over time}

B

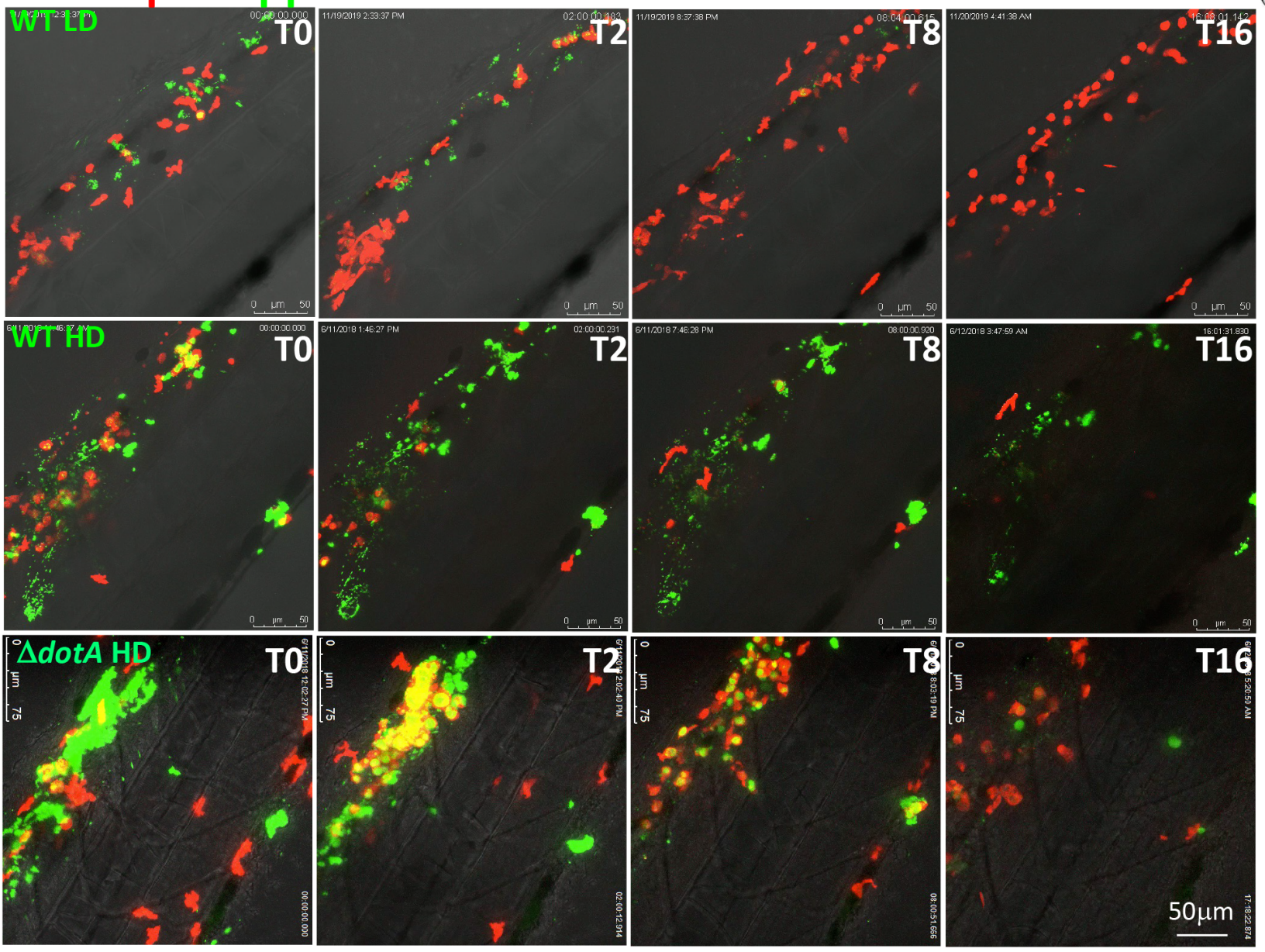


A

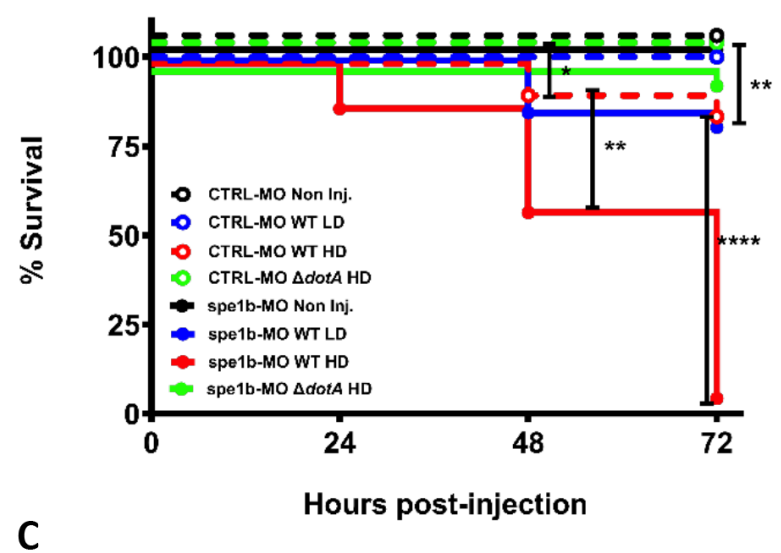

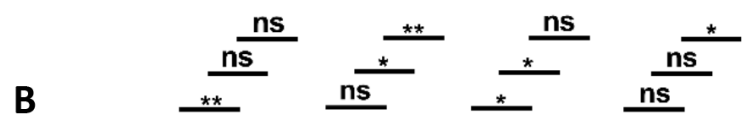

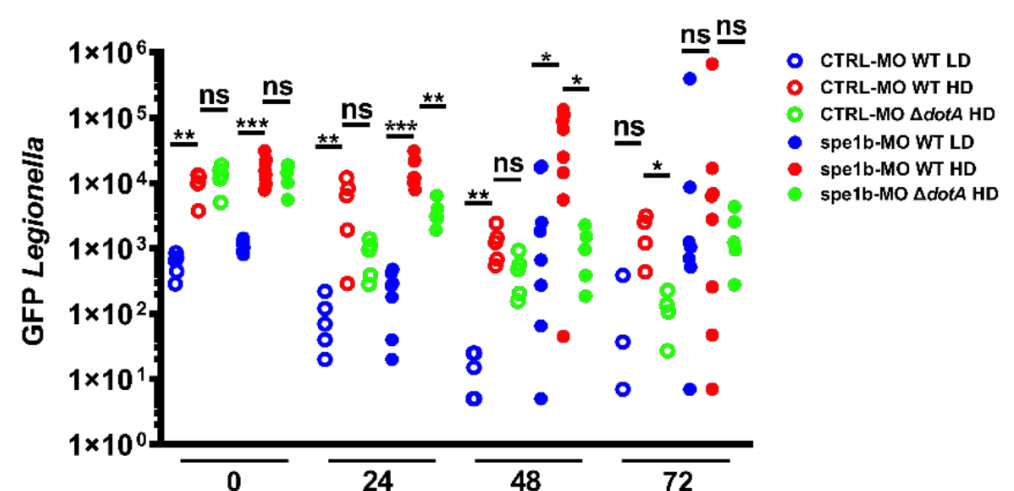

Hours post-injection

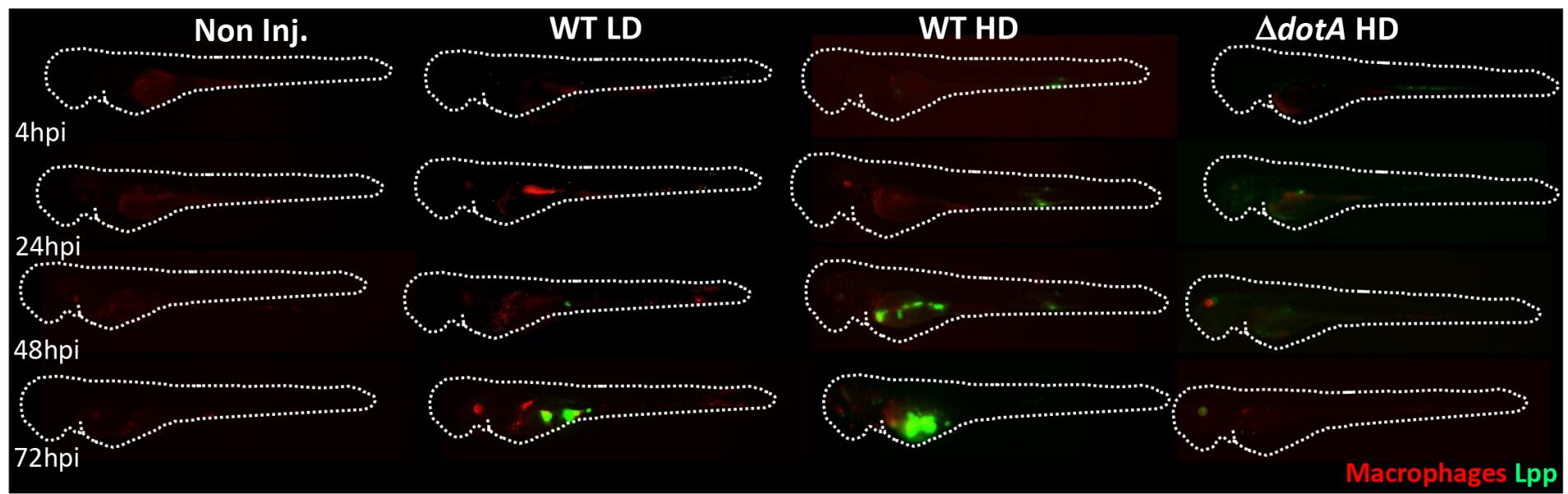

D

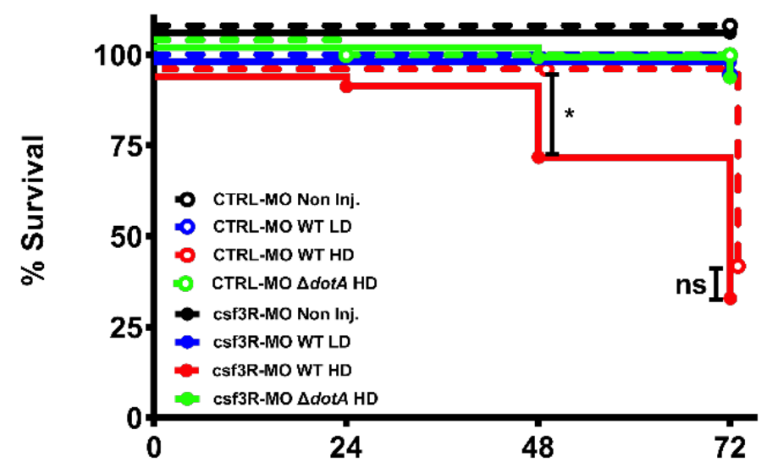

$\mathbf{F}$
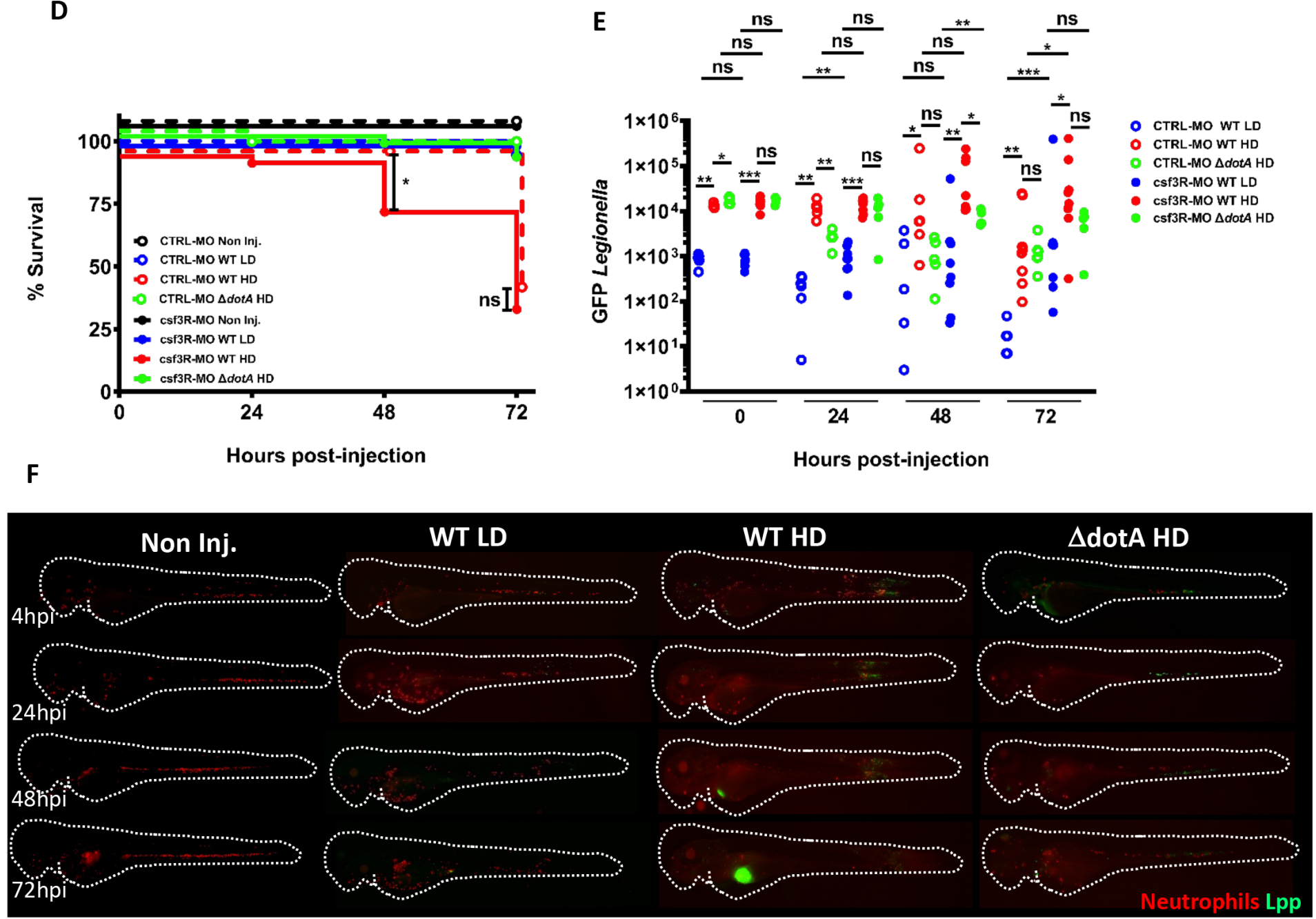


\section{A}

B

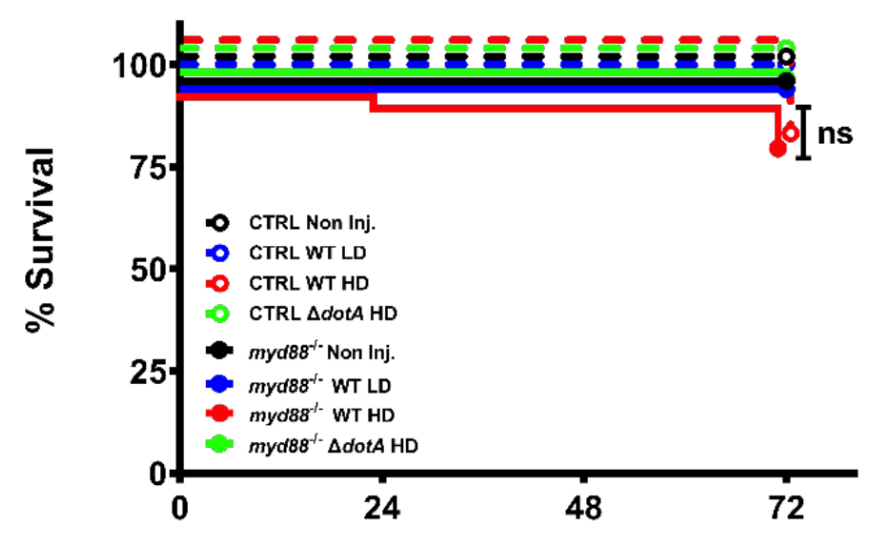

Hours post-injection
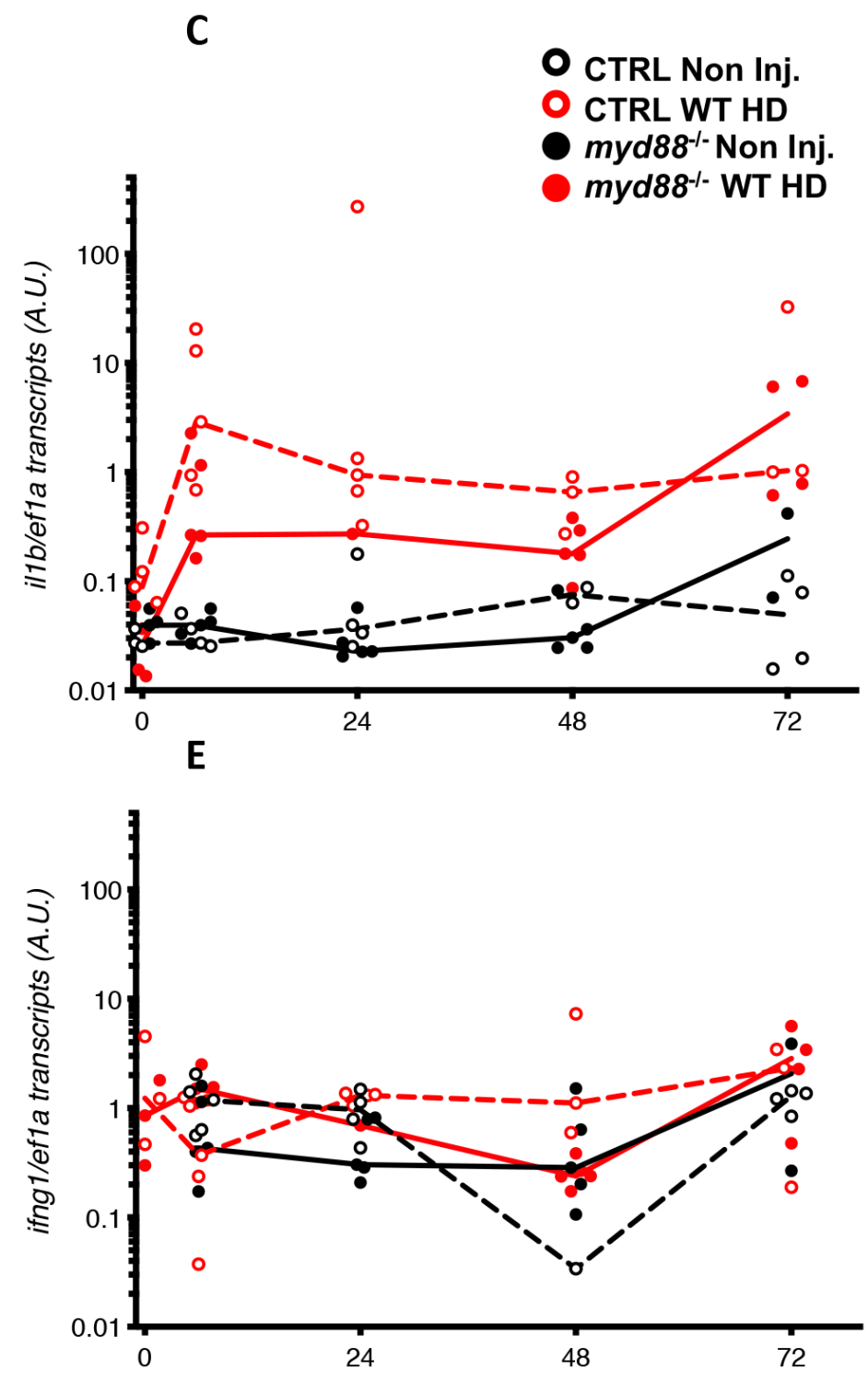

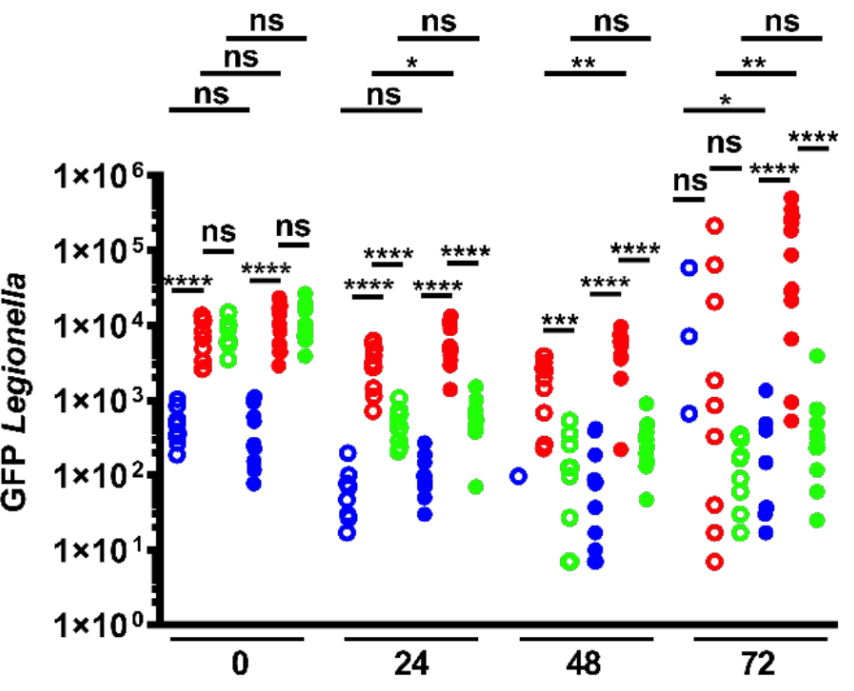

Hours post-injection

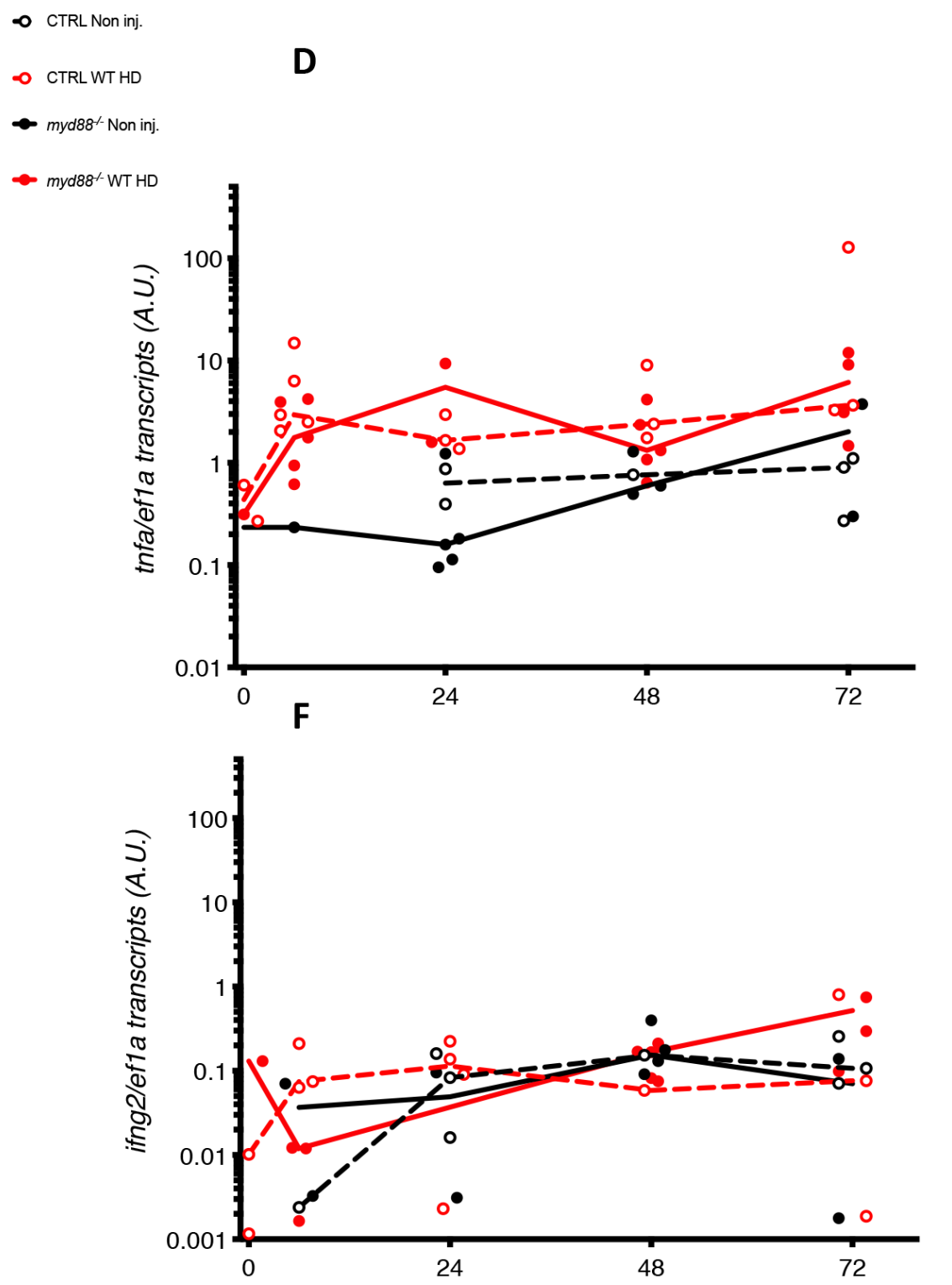


B

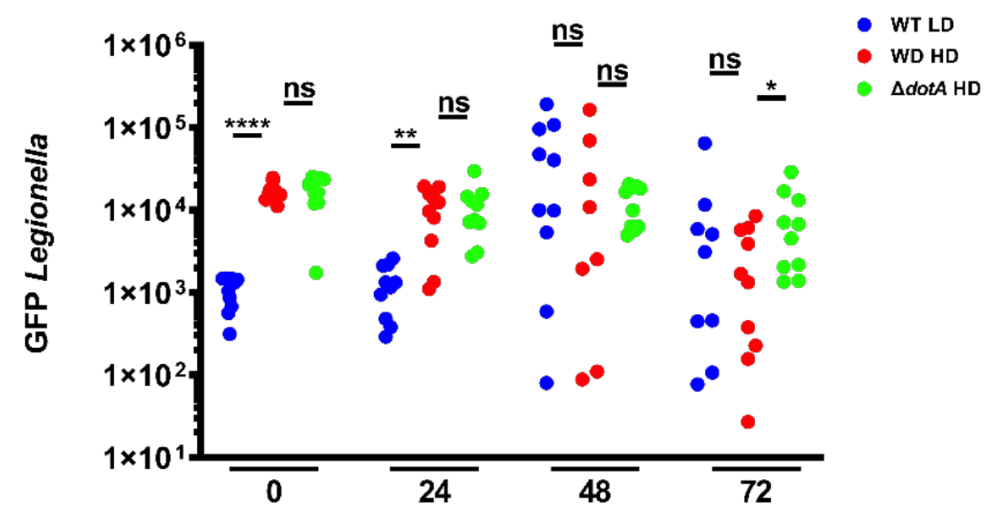

Hours post-injection

\section{Yolk injection}

A

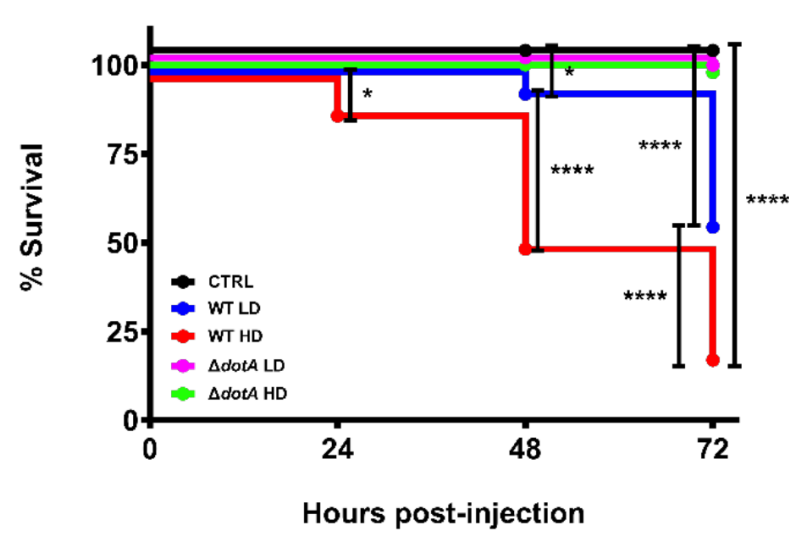

C

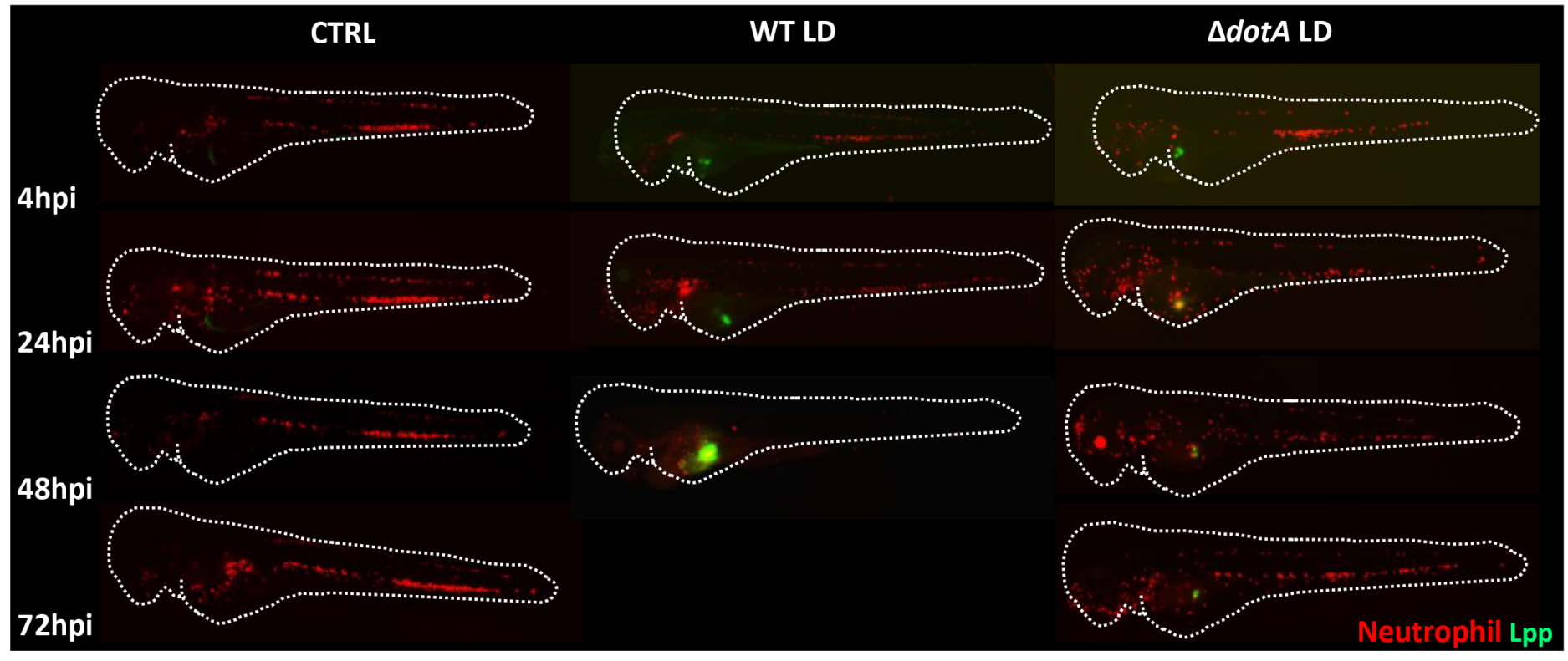

D
CTRL

WT HD

\section{$\Delta \operatorname{dotA} H D$}

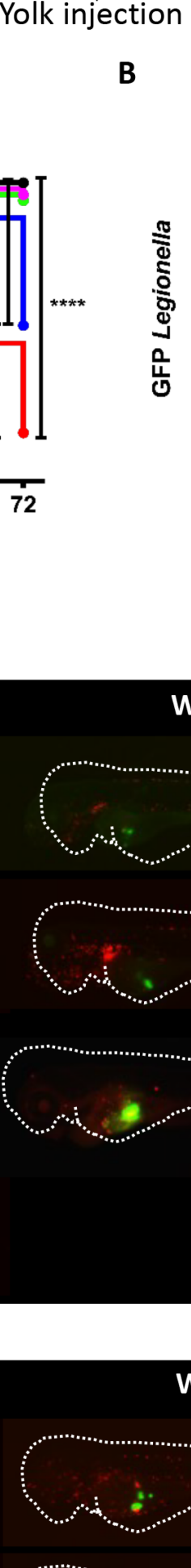

4hpi

24hpi 